https://helda.helsinki.fi

\title{
Microfluidic analysis techniques for safety assessment of pharmaceutical nano- and microsystems
}

\section{Sikanen, Tiina}

John Wiley \& Sons Ltd.

2020-10-30

Sikanen , T , Ollikainen , E \& Kiiski , I 2020 , Microfluidic analysis techniques for safety assessment of pharmaceutical nano- and microsystems . in L Peltonen (ed.), Characterization of Pharmaceutical Nano- and Microsystems . Advances in Pharmaceutical Technology , John Wiley \& Sons Ltd. , Hoboken , pp. 97-135 . https://doi.org/10.1002/9781119414018.ch3

http://hdl.handle.net/10138/334794

https://doi.org/10.1002/9781119414018.ch3

acceptedVersion

Downloaded from Helda, University of Helsinki institutional repository.

This is an electronic reprint of the original article.

This reprint may differ from the original in pagination and typographic detail.

Please cite the original version. 


\title{
Characterization of Pharmaceutical Nano- and Microsystems
}

Editor Leena Peltonen, John Wiley \& Sons, Ltd.

\section{Chapter 3.}

Microfluidic analysis techniques for safety assessment of pharmaceutical nano- and microsystems

\section{Authors:}

Tiina M. Sikanen, Iiro Kiiski, Elisa Ollikainen

\section{Authors' address:}

Faculty of Pharmacy, Drug Research program, University of Helsinki, Viikinkaari 5E, FI-00790 Helsinki, Finland

\section{Correspondence to:}

Tiina M. Sikanen, Tel. +358-2941-59173, Email: tiina.sikanen@helsinki.fi

\section{Keywords:}

Microfluidics, Microfabrication, Organ-on-a-chip, Immobilized enzyme reactors, Microchip electrophoresis, Drug metabolism

\begin{abstract}
Microfluidics is increasingly applied to chemical and biological research, including drug discovery and development This chapter gives an overview of the commonly used microfabrication methods and materials as well as microfluidic (bio)analytical techniques available for the in vitro safety assessment of pharmaceutical nano- and microsystems. A general overview will be given to the evolution of microfabrication methods and materials, which have facilitated the progressive development of microfluidic cell culture platforms (so called organ-on-a-chips), immobilized enzyme microreactors, and integrated separation systems (for chemical analysis). Of these techniques, the organ-on-a-chips are so far the most applied microfluidic concept in safety evaluation of pharmaceutical nano- and microsystems, whereas the other two represent techniques that could benefit the field in the future by enabling in-depth mechanism-based studies with respect to, e.g., improved hepatic safety.
\end{abstract}




\section{Chapter 3}

\subsection{Microfluidic bioanalytical platforms}

Since 1990's, microfluidics has been increasingly applied to chemical and biological research, including drug discovery and development [1,2]. Microfluidics is by definition a field of study that encompasses the physics of fluid behavior in micrometer structures and the engineering aspects of design and fabrication of miniaturized devices for controlling the flow of small amounts of fluids (typically in the range of pico-nanoliters). Via microfabrication, all critical operations can be combined on a single microfluidic chip, including but not limited to fluid manipulation and mixing, sample purification and enrichment, (bio)chemical reactions, cell manipulation and culturing, as well as separation and detection of the chemical and biological sample components [3-5]. This field of research is often referred to as Micro Total Analysis Systems ( $\mu$ TAS) or Lab(oratory)-on-a-Chip. From the perspective of (bio)chemical analysis, the high degree of integration results in negligible dead volumes (no time lag) between the different units, which substantially decreases the total analysis time per sample. The analytical throughput may be further increased through microfabrication of multiple integrated assays in parallel. From the perspective of cell culturing, introduction of microfluidic flow enables, e.g., efficient supply of nutrients to and removal of metabolic waste from the cell cultures. In addition, microfluidic actuation enables creation of spatial chemical gradients and their precise control over time, which benefits especially mechanism-based studies on both organ and (single) cell levels. Overall, miniaturization also reduces the consumption of expensive and/or toxic chemicals, thus saving resources and producing less chemical waste.

Besides (bio)analytical techniques, microfluidics has been extensively applied to custom manufacturing, i.e., synthesis and functionalization, of pharmaceutical nano- and microsystems, but these are categorically out of the scope of this book. For an overview of the state-of-the-art in this field, the reader is advised to familiarize with other recent reviews focusing on microfluidic techniques in drug delivery [6,7]. Here, the aim is to provide the reader with an idea of the rationale design of microfluidic (bio)analytical devices, paying particular attention to the possibilities and limitations associated with the applicable microfabrication methods and materials.

\section{Section 3.1.1 Microfabrication methods and materials}

In this section, the evolution of microfabrication methods and materials, applicable to manufacturing of micro total analysis systems (or lab-on-a-chips), is reviewed from the general perspective. The materials properties critical to each reviewed application field are further emphasized in later sections. 
The progressive development of silicon microfabrication processes in the early 1980's enabled the explosive growth of semiconductor technology so that electrical components (transistors, diodes, integrated circuits, solar cells etc.) could be fabricated at practically zero cost and mobile electronic devices became available to average users. In the 1990's, the same microfabrication processes were harnessed for manufacturing of miniaturized chemical analysis devices that incorporated integrated micrometer-scale channels for sample loading and electrophoretic separation on a single chip [8,9]. Although the first silicon-based gas chromatographic separation chip was reported already at the end of 1970's [10], the greater breakthrough emerged via the introduction of glass micromachining techniques to fabricate microfluidic electrophoresis devices [8,9]. This was because the concept of microchip electrophoresis, on an electrically insulating material such as glass, facilitates substantial decrease in the duration of analysis down to ca. 1 min per sample (for more details, see Section 3.4). However, microfabrication of glass by wet or plasma etching requires specialty cleanroom equipment and relatively harsh chemicals, such as hydrogen fluoride [11], which significantly limits the use of glass-based microfluidics in regular research laboratories. Therefore, the introduction of poly(dimethyl siloxane) (PDMS) soft lithography in 1998 [12,13] was the critical next step to wider exploitation of microfluidics in chemical and biological research by enabling rapid replication of microfabricated structures in normal laboratory conditions.

In PDMS soft lithography, a master mold is typically prepared (in cleanroom conditions) by transferring the microstructures from a photomask to a photoresist (such as the negative tone epoxy polymer SU-8 [14,15]), spincoated on a silicon wafer, by UV lithography (Figure 1). The photomask is typically based on a computer-aided drawing (CAD) translated into a chromium-coated glass plate, although nowadays the quality and feature resolution of printed plastic masks (less expensive) are often sufficient for most microfluidic applications. The silicon wafer (typically 4-inch in diameter) supporting the photoresist pattern is the standard borrowed from semiconductor industry, as is the UV lithographic patterning of photoresists to reproduce the photomask design onto the silicon wafer. Several commercial vendors exist for both types of photomasks and silicon (and glass) wafers as well as for both negative and positive tone photoresists. In the case of negative tone photoresists, the areas exposed to UV will crosslink, whereas the masked areas do not and can be dissolved using appropriate developer solution, in analogy to photography (Figure 1). In a subsequent step, the microstructures of the master mold will be replicated to PDMS by pouring the elastomer solution onto the master, crosslinking the PDMS by heating, and detaching the PDMS replica from the master mold [12,13], as illustrated in Figure 1. Although in this protocol the master fabrication typically still relies on cleanroom processes, the subsequent PDMS crosslinking can be performed in regular laboratory conditions and the master typically tolerates reproduction of multiple PDMS replicas, which 
significantly reduces the cost and complexity of microfabrication. Equally important is also the fact that PDMS is self-adhesive to itself and to most other materials, which enables straightforward sealing of the PDMS microstructures [12,13]. The PDMS-PDMS bonding is by default reversible in nature, but permanent bonding of two PDMS layers for applications requiring higher pressures (>1 bar) may be achieved by treating the surfaces with, e.g., oxygen plasma prior to their bonding [16]. For comparison, sealing of glass or silicon based microstructures with another glass/silicon wafer is much more complicated and typically requires high temperatures or specialty equipment [11].



Figure 1. Schematic representation of the typical PDMS soft lithography process. Republished with permission of the Royal Society of Chemistry, from Huikko et al.2003 [17]; permission conveyed through Copyright Clearance Center, Inc.

Besides manufacturing of PDMS-based microfluidic devices, the PDMS replica itself can also be used as a stamp or a mold for further replication steps as illustrated in Figure 2. In principal, the PDMS microstructures can be replicated to any heat- or UV-curable polymer by casting the monomer solution onto the PDMS mold, crosslinking the cast polymer when in contact with PDMS, and detaching the new polymer replica from the PDMS mold. The lifetime of the PDMS mold is typically less than that of the cleanroom master molds, because PDMS tends to absorb the monomers of the cast solution, but it easily lasts for at least a handful of repeated replication cycles [18]. In comparison to direct replication of heat- or UV-curable polymers (other than PDMS) with the help of cleanroom masters (e.g., SU-8), the elasticity of PDMS plays a critical role in facilitating straightforward 
detachment of the mold and the replica from each other (after curing) without damaging the reproduced microstructures. If both the mold and the replica are mechanically rigid materials, the detachment is much more complicated. Thereby, the introduction of PDMS soft lithography at the end of 1990's significantly increased the freedom in selection of the microfabrication material on a best-fit-for-the-purpose basis so that the materials (properties) could be chosen from the end application viewpoint. However, not all polymers can be sealed in an equally straightforward manner as PDMS devices, since most other polymers do not feature self-adhesive properties. An exception are, e.g., UV-curable off-stoichiometric thiol-ene (OSTE) polymers, which - depending the bulk monomer composition and the applied crosslinking conditions - may be sealed by one another following a fairly simple lamination protocol $[19,20]$. In addition to straightforward sealing, the OSTE chemistry provides the possibility to adjust both the bulk properties and the surface chemistry (type and number of functional groups available for further chemical conjugation reactions) on the basis of the end-application needs [18,20-22]. These possibilities are briefly reviewed in the context of relevant applications in the next sections.

a) SU-8 master

b) PDMS soft lithography

c) Thiol-ene replication
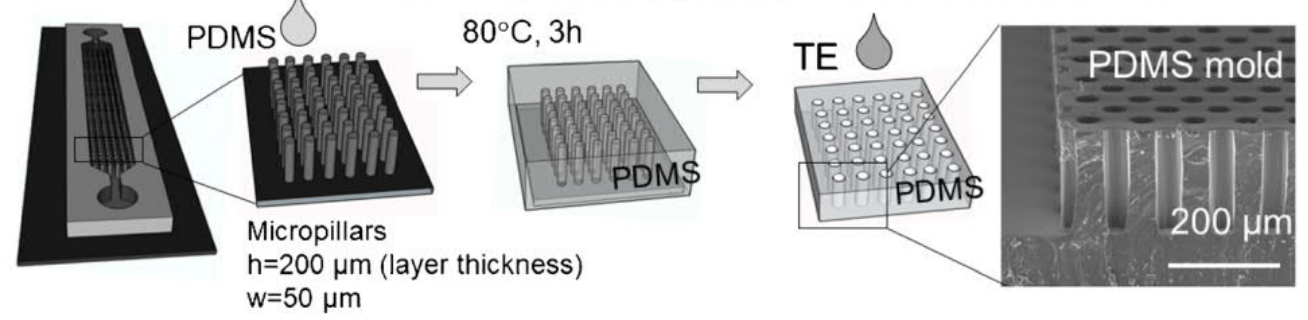

Vacuum treatment and curing

d) Lamination and bonding
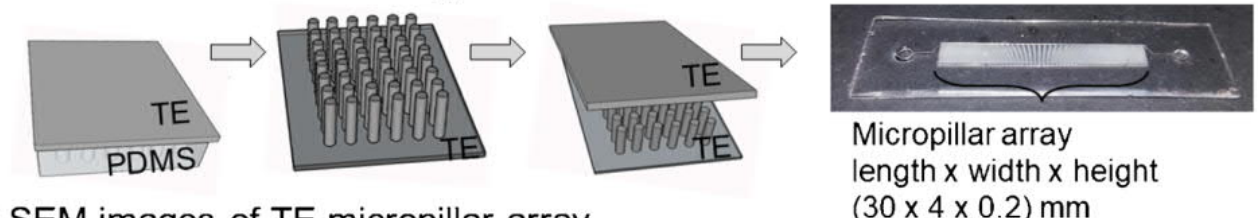

e) SEM images of TE micropillar array


Figure 2. Schematic presentation of the fabrication steps of micropillar arrays reproduced in UVcurable, off-stoichiometric thiol-ene (TE) polymers: (a) SU-8 master fabrication in cleanroom, (b) PDMS soft lithography, (c) TE replica-molding: pouring TE monomer solution onto the PDMS mold, removal of trapped air in vacuum and crosslinking by UV, and (d) sealing of the cured micropillar layer by another (flat) TE layer by lamination and further UV curing of the bonded interface. (e) 
Scanning electron microscopy (SEM) images of the micropillar arrays. Republished with permission of Springer Nature, from Tähkä et al. 2019 [18]; under the terms of the Creative Commons Attribution 4.0 International License.

To date, a wealth of polymers, primarily UV-curable or thermoplastic, have been introduced for prototyping of microfluidic devices by replication (e.g., soft lithography, embossing) or direct microfabrication methods (e.g., lithography, micromachining) [23]. Thermoplastic materials, on one hand, can be cost-efficiently processed by a variety of techniques, including injection molding, thermoforming, hot embossing, laser machining, and precision mechanical machining [24]. On the other hand, direct UV lithography of negative tone photoresists, such as SU-8 [14,15] and organically modified ceramics [25,26], typically provides superior feature resolution compared with other microfabrication techniques. In recent years, the progressive development and the low-cost of 3D printing has also significantly increased the use of fused deposition modeling and stereolithography for additive manufacturing of both master molds and micro-millifluidic devices [27,28]. All of these techniques together currently provide versatile possibilities for rapid prototyping of microfluidic devices in both cleanroom and regular laboratory settings. The selection of the proper material and method can in most cases be made from the perspective of the critical materials properties required in the end application. However, a technology barrier still exists in terms of translating the prototypes into commercially viable microfluidic products, since not all materials are feasible for massmanufacturing. Commercial vendors primarily exist for glass-based microfluidic devices as well as for thermoplastics. Lately, roll-to-roll manufacturing has also been introduced to mass production of PDMS [29] and thiol-ene [30] microdevices, which may pave the way for their commercial use as well.

\section{Section 3.2 Microfluidic cell cultures}

In this section, the possibilities and limitations associated with microfluidic cell culturing, or so called organ-on-a-chip technology, are briefly reviewed together with selected examples of their exploitation to characterization of pharmaceutical nano- and microsystems. Since comprehensive reviews of the previous literature in this field have been published elsewhere [31], the emphasis in this chapter will be on the design of organ-on-a-chips from the perspective of the microfabrication methods and materials (selection). 


\section{Chapter 3}

\section{Section 3.2.1 Selection of the microfabrication material by design}

Compared with conventional static cell cultures, microfluidic cell culturing benefits from efficient nutrient supply and improved elimination of metabolic waste thanks to the through-flow applied over the cells seeded onto the microchannel bottom (Figure 3). However, differences in proliferation, glucose metabolism, signaling pathway activation and protein expression levels between cells cultured in traditional macroscale cultures and in microfluidic cultures have also been reported [32]. Much of the original work on organ-on-a-chip development has centered around fully PDMS based or PDMS-glass hybrid devices, not only because of the straightforward prototyping, but also because of the inherent bio- and cell compatibility and superior optical transparency (down at the UV range) of PDMS [33]. Moreover, PDMS also has high oxygen permeability [34], which is critical to ensuring sufficient oxygen transfer to the cell culture through the cover (PDMS) layer, especially during the static (no-flow) cell seeding step. On their own, neither PDMS nor glass readily support cell adhesion (at the bottom of the microchannel), and therefore the microchannel is typically coated with proteins promoting cell adhesion prior to cell seeding [33]. However, readily cell-adherent and biocompatible microfabrication materials also exist, such as the commercially available organically modified ceramics [35-37]. Besides materials properties, the spatial confinement and shear force impact cell adhesion and proliferation (Figure 3). On one hand, care should be taken to adjust the microfluidic flow rate so as to ensure that the shear stress does not exceed the threshold for cell adhesion [38]. On the other hand, manipulation of the shear force is a prerequisite to ensure physiologically relevant conditions in, e.g., vascular cell cultures [39]. The cell-compatibility of the chosen microfabrication material may also be affected by chemicals (e.g., uncrosslinked monomers) leaching from the bulk to the cell culture medium, which limits especially the use of many polymers (other than PDMS) in organ-on-a-chip applications. For example, the leaching monomers of methacrylate-based cell culturing platforms have been reported to induce apoptosis of human osteoblasts [40]. Similar material-induced cell death has also been associated with certain 3D printing [41] as well as thiolrich OSTE polymers [42]. To eliminate the impacts of leaching chemicals, particular attention thus needs to be paid on post-processing of the cell culture platforms prior to cell seeding. Typically relatively simple heat treatment, possibly combined with a pre-incubation in the culturing medium, has sufficed to eliminate the leaching monomers [40,43]. 




High volume:

Mesenchymal phenotype

Epithelial phenotype
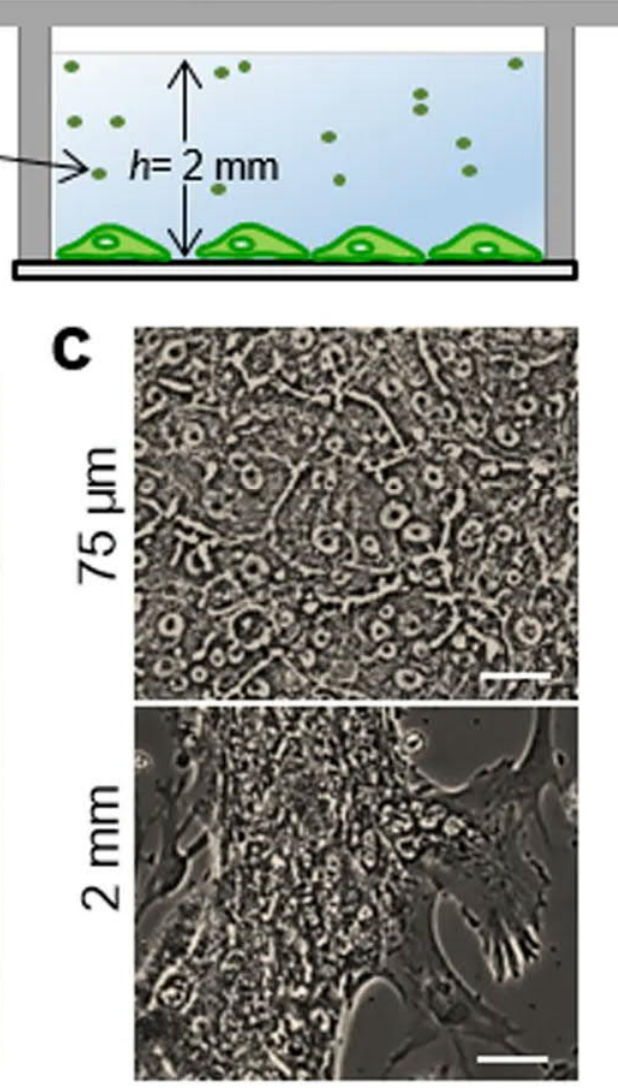

Figure 3. (a) Illustration of the difference in phenotype of primary hepatocytes in small vs. large volumes, suggested to arise from the accumulation of endogenous factors in small volumes (h is the height of cell culture chamber). (b) A PDMS-based microdevice perfused with food dye. (c) Bright field images of primary hepatocytes after seven days in 12-well plate $(\mathrm{h}=2 \mathrm{~mm})$ or inside the microfluidic device $(\mathrm{h}=75 \mu \mathrm{m})$. Scale bar is $25 \mu \mathrm{m}$. Republished with permission of Springer Nature, from Haque et al. 2016 [44]; under the terms of the Creative Commons Attribution 4.0 International License.

The optical properties (clarity and transparency) of the chosen microfabrication materials mainly determine the suitability of the different cell stains for visualization of cell viability and/or apoptotic biomarkers. Apart from PDMS, many polymers exhibit fairly high autofluorescence in the near UV range and below [45], although for instance organically modified ceramics and OSTE polymers too are optically clear and transparent down to ca. $300 \mathrm{~nm}[46,47]$ almost same as glass. To a certain degree, the optical clarity also depends on the chosen microfabrication method. For example, 3D printing by default results in a rough and thus somewhat opaque surface compared with lithographically defined microstructures or the replicated patterns thereof [48]. Because of these reasons, hybrid devices made from PDMS (top layer) and glass (bottom layer) are probably the most used prototype design for organ-on-a-chips, as this configuration enables high quality optical 
monitoring of the on-chip cell culture by both inverted and upright microscopy (see, e.g., Figure 3). Besides optical detection, electrical impedance spectroscopy can be applied as a label free, noninvasive method for monitoring the growth-rate (or disruption) of the cell monolayers on microfluidic devices [49]. This approach however requires integration of conductive (metal) electrodes at the bottom of the microchannel, which sets certain limitations to the material selection. Namely, the electrode material has to be cell-compatible (such as gold or indium tin oxide) [50,51] and the substrate material (microchannel bottom) has to support metal adhesion. Metallization processes (sputtering or evaporation) typically rely on cleanroom equipment, but are fairly well established for e.g., glass. Instead, metallization of polymers typically suffers from poor adhesion (especially on PDMS [52]) and necessitates development of custom, material-specific processes (see, e.g., metallization of organically modified ceramics [53]). At best, however, combination of optical and impedance detection allows for long-term culturing with continuous parallel and mutually independent monitoring of the cell growth rates by means of impedance measurements and of specific other cellular events by means of optical or fluorescence microscopy [49].

Besides facilitating cell adhesion and proliferation, and their uninterrupted monitoring, careful selection of the microfabrication materials enables the design of fairly complex organ-on-a-chip platforms. For example, it is well-known that the atmospheric oxygen levels (21\%) are suboptimal to cell culturing from the perspective of in vitro-in vivo correlation [54]: in the physiological conditions (oxygen levels in the body range from 1 to $12 \%$ ), or under hypoxia, the cells grow faster, live longer, and show lower stress. In addition to conventional approaches (adding nitrogen gas to the cell incubator), hypoxic conditions can also be reproduced on chip, for example by adding oxygen scavenging chemicals to the liquid feed [55]. In this case, however, the microfluidic oxygen sink often has to be physically separated from the cell culture compartment, so as to avoid the toxic oxygen scavengers from attacking the cells. Figure 4 describes a schematic overview of a chip design, where a PDMS membrane was exploited to prevent the chemical diffusion into the cell culture (on top of the membrane), while allowing for oxygen transfer from the cell culture to the underlying chamber where oxygen scavenging was chemically induced. In this case a vertical oxygen gradient was created across the atmospheric cell culture (Figure 4), but to achieve uniform hypoxia, attention has to be paid on the use of gas impermeable materials only, so as to prevent oxygen transfer to the cell culture through the microchannel cover layer. The oxygen permeability of most other microfabrication materials is insignificantly small compared with PDMS [56] and does not thereby set limitations to the material selection from the design perspective. Besides chemical additives, it has been reported that certain thiol-rich OSTE polymers feature inherent oxygen scavenging properties, which can be controlled by simply changing the surface-to-volume ratio of the microfluidic channel or the 
temperature and the curing time during the fabrication process [43]. Although the inherent oxygen scavenging capability of thiol-rich OSTE polymers is long-lasting, and thus feasible for long-term cell culturing under hypoxic conditions, it is associated with excess of uncrosslinked thiol monomers and thus disappears during the heat treatment required to avoid the material-induced cell death of OSTE polymers.

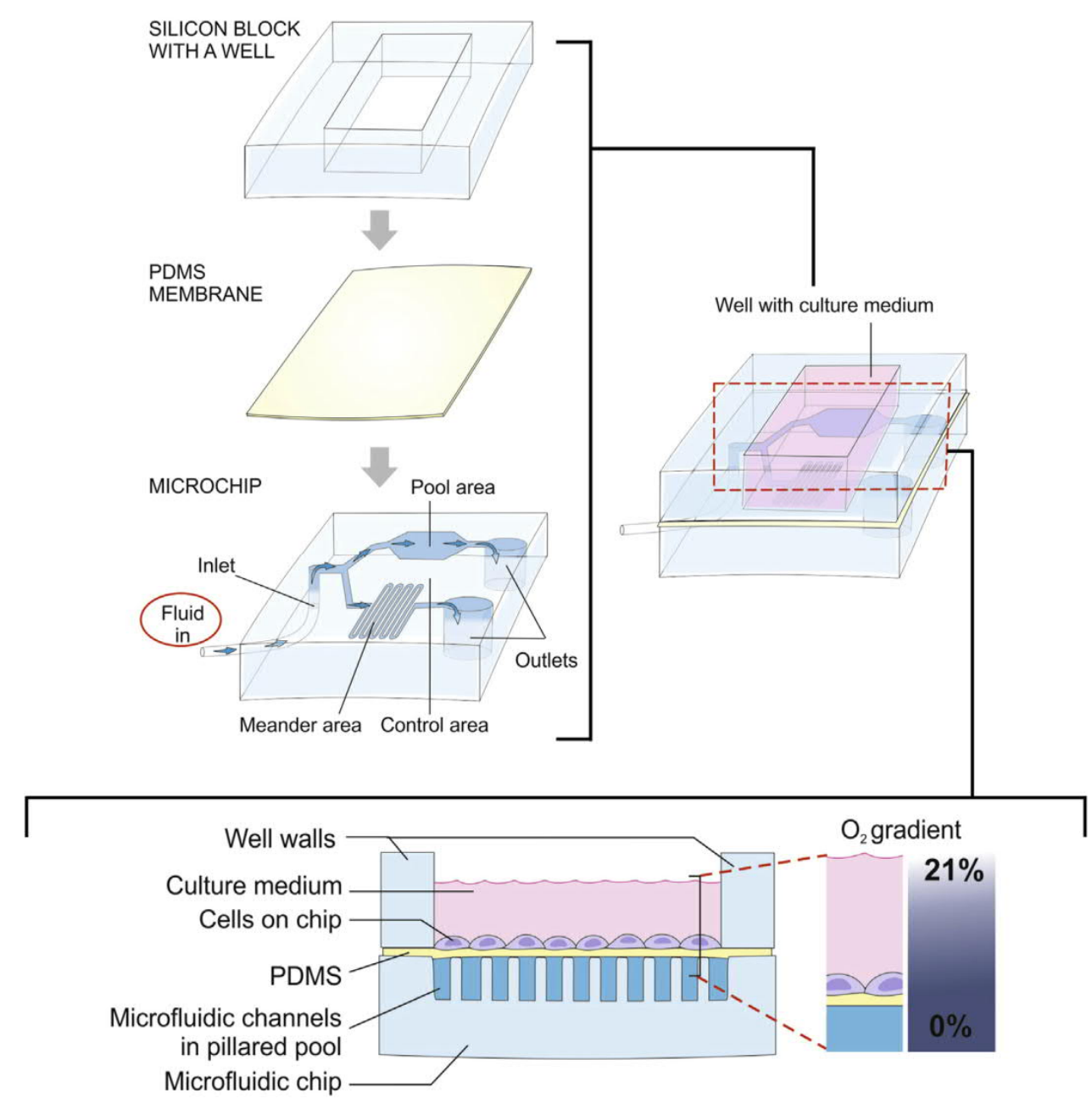

Figure 4. A schematic presentation of the microfluidic organ-on-a-chip used for creating hypoxic conditions on chip, while simultaneously isolating the toxic oxygen scavenging chemicals from the cell culture compartment with the help of PDMS membrane. Republished with permission of Elsevier, from Barmaki et al.2018 [55]; permission conveyed through Copyright Clearance Center, Inc.

\section{Section 3.2.2 Additional design considerations}

Materials selection plays a pivotal role in terms of ensuring the cell adhesion and viability as well as defining the prevailing culture conditions (especially oxygen level) inside the microfluidic channels. Besides the surface chemistry and wetting properties, inducing cell alignment via engineered 
topographical cues may elicit a cellular phenotype similar to aligned tissues in vivo [57]. The topography of the microchannel surface may be easily manipulated by microfabrication means. A common approach is to make use of microfabricated (on axis) grooves, which resemble the groovelike topographical features of the extra-cellular matrix. The impacts of topographical cues, in combination with and in the absence of microfluidic flow, have been particularly studied with a view maturation of induced pluripotent stem cell-derived cardiomyocytes (iPSC-CM) [58,59], although they are also beneficial for cell types of skeletal and neuronal lineages [60,61]. The microgrooves alone have been shown to bring about cellular alignment $(\mathrm{p}<0.0001)$ and more organized sarcomeres (Figure 5), and thus improved $\mathrm{Ca}^{2+}$ cycling not associated with modifications in gene expression of iPSC-CMs [58]. The synergistic impact of topographical cues and sustained release of biochemical growth factors has been reported to improve even differentiation of human mesenchymal stem cells toward myogenic lineage [61].
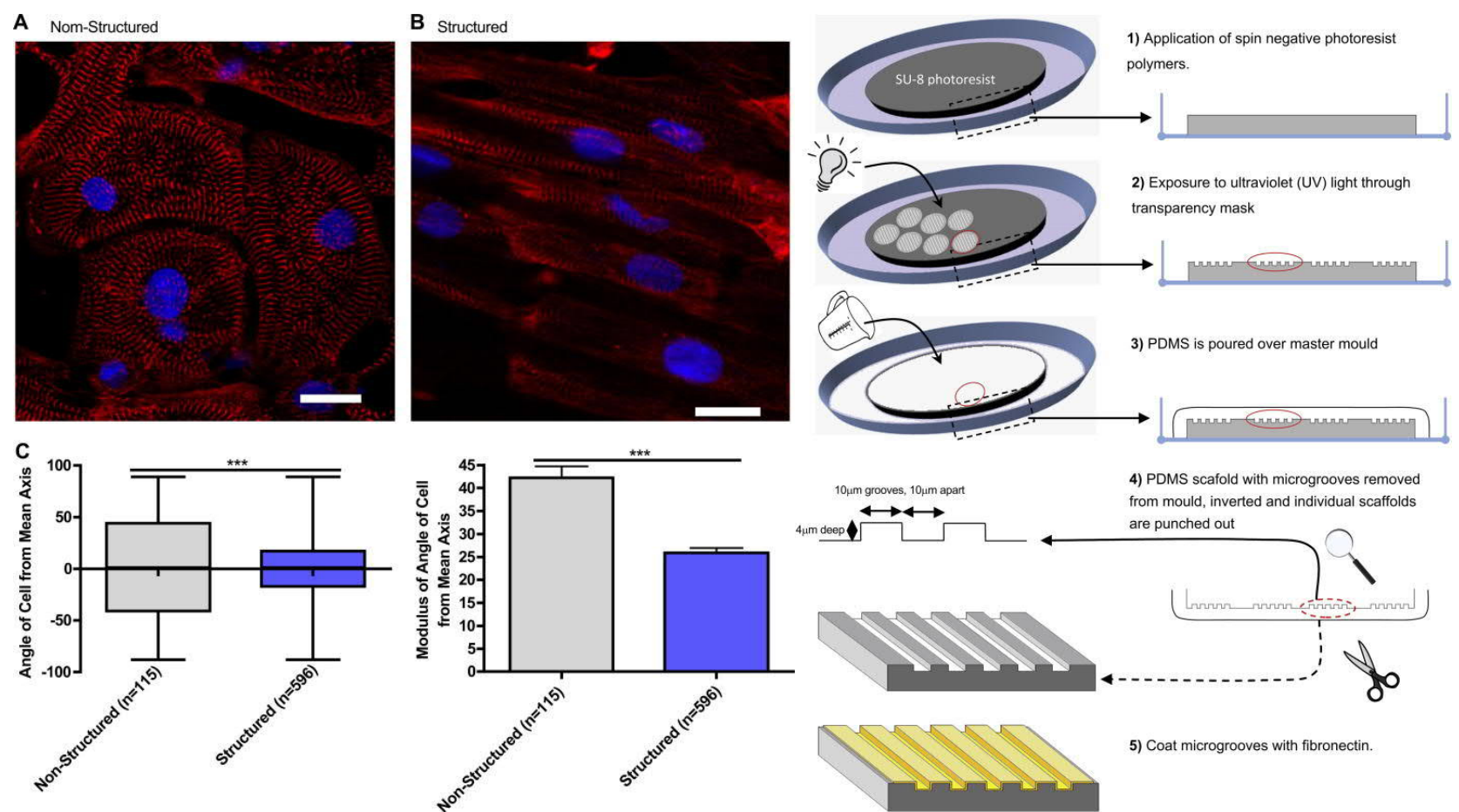

Figure 5. Left: Representative immunofluorescence of iPSC-CM cultured on unstructured PDMS (A) and microgrooved PDMS (B), Red - sarcomeric $\alpha$-actin, Blue - DAPI, scale bar $20 \mu \mathrm{m}$. Quantification of cell alignment iPSC-CM on structured and unstructured constructs (C). Right: Schematic demonstrating the fabrication of microgrooved tissue culture substrates (not drawn to scale). Republished with permission of Elsevier, from Rao et al. 2013 [58]; under the terms of the Creative Commons Attribution 4.0 International License.

Along with cell monolayers, microfluidic three-dimensional (3D) cell culturing techniques have received increased recognition by both researchers and administrators [62]. In 3D, the cells are known 
to retain tissue-specific architecture better than in monolayers [63,64], because the flat and rigid surface requires cytoskeleton to establish contact between neighboring cells and exert artificial polarity [65], which prevents the formation of adequate extracellular matrix (ECM) and the cell-cell and cell-matrix interactions [66]. Moreover, the lack of certain cell-specific functionalities in monolayer cultures (e.g., sub-physiological expression of metabolizing enzymes or cell polarization) favor the use of 3D cell models in modern drug discovery and development [67]. Overall, culturing cells in 3D often improves the accuracy of in vitro-in vivo correlation in cell-based safety and efficacy assessment. For example, the 3D tumor models are often more resistant to drug therapies compared with monolayer cultures [68]. The microfluidic 3D cell cultures can be established by a variety of techniques, including both scaffold-based (e.g., encapsulation of cells in 3D hydrogels) and scaffoldfree strategies, such as forced floating in hanging drops or in cell-repellant microwells that result in the formation of spherical cell aggregates $[62,69]$. However, the increasing complexity does not automatically mean better results. For example, the diffusion-limited penetration of antibodies and other cell stains are prevailing challenges commonly associated with 3D cell cultures, especially those exploiting scaffold-based strategies. Scaffold-based strategies also raise issues of biocompatibility and cell-material biorecognition, whereas biodegradable scaffolds substitute a large amount of ECM and result in 3D cultures composed of less densely packed cells [70]. In contrast, scaffold-free approaches initiate interactions between cells which aids the formation of self-generated ECM. Compared with conventional scaffold-free methods, often featuring limited reproducibility and size uniformity, microfluidic 3D cell culturing devices hold the promise of high-throughput in both generation and handling of multitude of uniform-sized spheroids on a single platform [69]. Fabrication of microwells, and particularly their integration with microfluidic channels, is generally more straightforward than that of hanging drop devices. However, achieving cell-repellant surfaces to induce forced floating in microwells, as illustrated in Figure 6, typically requires additional postprocessing steps. The common approaches taken to reduce cell adhesion include, e.g., pegylation [71] and nanostructuring of hydrophobized surfaces [72,73]. Moreover, most microfabrication methods and materials yield vertical or near-vertical walls, i.e., cylindrical microwells, which are sub-optimal to controlling the spheroid growth. Although substantial effort has gone on development of methods feasible for reproducing rounded microstructures (cross-section profiles), their fabrication is generally challenging and in most cases relies on nonstandard techniques, such as overexposure of organically modified ceramics [26] or replica-molding of microdroplet-shaped features obtained via photoresist reflow [74]. Many of the other available techniques, such as isotropic etching [75], laser ablation [76], and milling [77], are limited in terms of achievable aspect ratio (height/width), which may set limitations to total culturing time due to spheroids outgrowing the microwells. Nevertheless, U-shaped microwells are preferred for on-chip spheroid culturing, because in cylindrical microwells, 
the cells are initially located far apart from each other, which may impair the cell-cell interactions and subsequently reduce the reproducibility and size uniformity from well to well. Increasing the initial cell count or decreasing the well dimensions often improve reproducibility, but simultaneously limit the total culturing time as the spheroids outgrow the wells sooner. In contrast, U-shaped wells enable single-pointed gravitational force, which brings the cells closer to each other even in relatively large wells resulting in superior reproducibility [78].

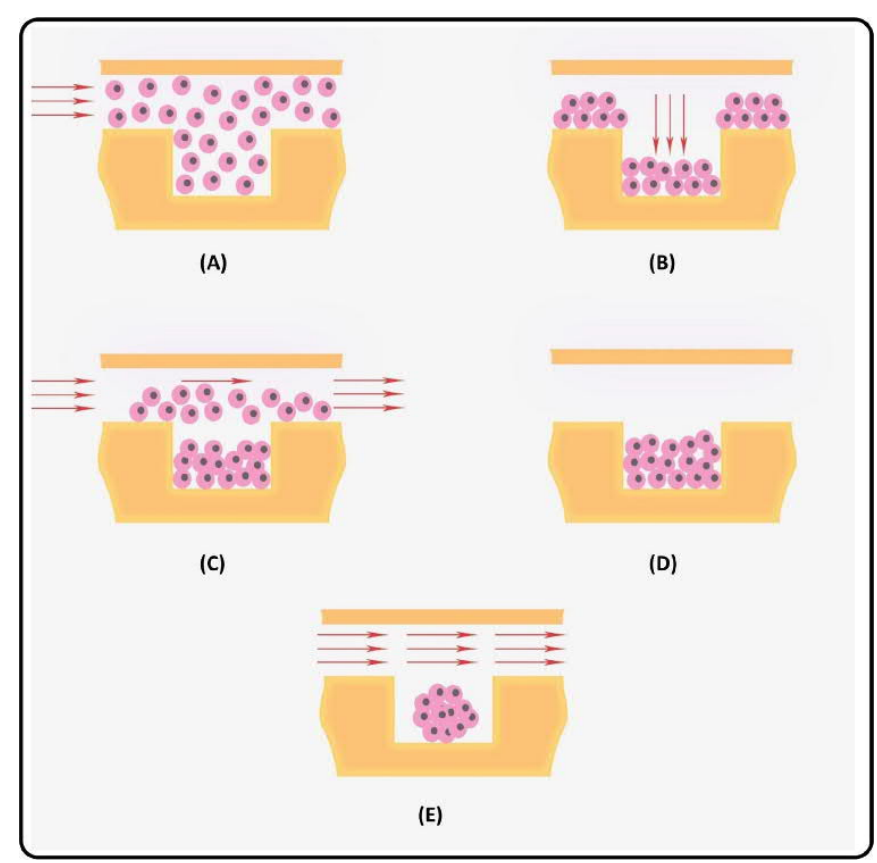

Figure 6. Spheroid formation process in a microwell-based organ-on-a-chip: (A) Introduction of a cell suspension to the chip inlet. The cell suspension fills all the microchannels and microwells rapidly due to the capillary effect; (B) Cells start depositing on the bottom of the microchannels and microwells; (C) Pure culture medium flows through the chip to rinse the excess cells without disturbing the cells lying on the microwell bottom; (D) Cell secretions and signaling lead to establishment of cell-cell interactions on the non-adherent microwell bottom; (E) Driving spheroid formation under a perfusing flow of culture medium. Republished with permission of Elsevier, from Moshksayan et al.2018 [78]; permission conveyed through Copyright Clearance Center, Inc.

\section{Section 3.2.3 Characterization of pharmaceutical nano- and microsystems using organ-on-a- chips}

By enabling simulation of dynamic fluid flows, chemical and oxygen gradients, and partitioning between organs, microfluidic organ-on-a-chips o $\square$ er a cost-e $\square$ icient approach to rapid in vitro screening of pharmaceutical nanocarriers in physiologically relevant conditions. As most pharmaceutical nanocarriers are intravenously administered into the blood, the preliminary work on 
microfluidic devices has addressed optimal nanoparticle (NP) design, e.g., via NP margination, e $\square$ ect of vessel geometry and shear stress on NP accumulation, interactions between red blood cells/platelets and NPs, and vessel permeability on NP translocation [31]. Microfluidic organ-on-achips have also been developed to assess the NP haemocompatibility [79] and NP transport across the blood-brain-barrier [80] and the alveolar-capillary barrier in the lungs [81]. The classical example of a microfluidic lung-on-a-chip device, capable of mimicking the mechanical distortion of the alveolar-capillary interface during normal breathing, is illustrated in Figure 7. Besides these selected examples, a variety of organ-on-a-chip models, including single cell traps, have been developed to enable assessment the cellular uptake and cytotoxicity of NPs under microfluidic flow, so as to avoid inaccuracies associated with, e.g., NP sedimentation (common to static cell cultures). For a more comprehensive overview, the reader is advised to familiarize with references [6,31].
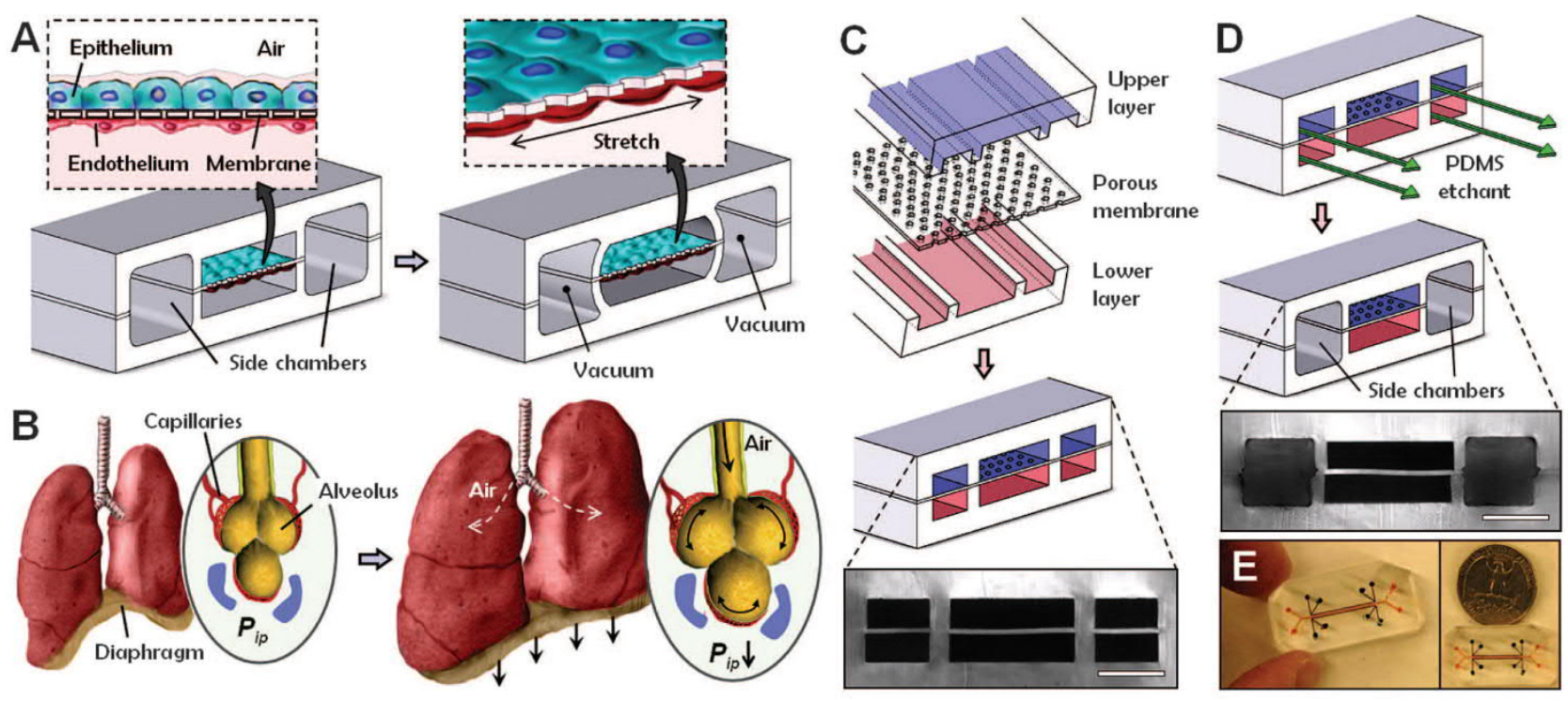

Figure 7. Biologically inspired design of a human breathing lung-on-a-chip microdevice. (A) The microfabricated lung-mimicking device uses compartmentalized PDMS microchannels to form an alveolar-capillary barrier on a thin, porous, flexible PDMS membrane coated with ECM. The device recreates physiological breathing movements by applying vacuum to the side chambers and causing mechanical stretching of the PDMS membrane forming the alveolar-capillary barrier. (B) During inhalation in the living lung, contraction of the diaphragm causes a reduction in intrapleural pressure (Pip), leading to distension of the alveoli and physical stretching of the alveolar-capillary interface. (C) Three PDMS layers are aligned and irreversibly bonded to form two sets of three parallel microchannels separated by a 10-mm-thick PDMS membrane containing an array of through-holes with an effective diameter of $10 \mathrm{~mm}$. Scale bar, $200 \mathrm{~mm}$. (D) After permanent bonding, PDMS etchant is flowed through the side channels. Selective etching of the membrane layers in these channels produces two large side chambers to which vacuum is applied to cause mechanical 
stretching. Scale bar, $200 \mathrm{~mm}$. (E) Images of an actual lung-on-a-chip microfluidic device viewed from above. Republished with permission of the American Association for the Advancement of Science, from Huh et al.2010 [81]; permission conveyed through Copyright Clearance Center, Inc.

\section{Section 3.3 Immobilized enzyme microreactors for the hepatic safety assessment}

The possibility for targeted identification and treatment of tumors remains one of the main drivers of nanomedicines development [82]. However, the challenges associated with the selectivity of NP targeting to tumors [82] often results in substantial accumulation and sequestering of NPs to the liver, by estimates up to 30-99 \% of the administered dose [83]. NP accumulation to the liver inevitably results in reduced NP delivery to the tumor and potentially leads to increased hepatic toxicity at the cellular level, thus creating a major barrier to clinical translation of NP-based therapies. As a result, the clinical benefits of NPs so far have mainly arisen from formulations that improve the pharmacokinetics and toxicity profiles of, e.g., chemotherapeutic agents [84]. This section focuses on the hepatic safety assessment of nanoparticles (NP) and gives an overview of the development of microfluidic immobilized enzyme reactors that could facilitate examination of the hepatic (adverse) effects of nanomedicines under physiologically relevant conditions. In comparison to cell-based in vitro models, the subcellular enzyme assays likely enable more detailed assessment of the mechanistic basis of possible NP interactions once uptaken by cells. Similar to cell-based assays, conducting these experiments under microfluidic flow will help to avoid inaccuracies associated with, e.g., NP sedimentation. Microfluidic actuation also allows for precise control of the NP exposure time so as to determine whether the possible impacts are reversible or permanent in nature.

\section{Section 3.3.1 Nanoparticle impacts on the hepatic clearance of xenobiotics}

The nonspecific accumulation of NPs within the liver can be explained by its normal physiology. Since the metabolism and clearance of foreign materials are the primary functions of the liver, engineered NPs that cannot be cleared by the renal system (threshold ca. $>6 \mathrm{~nm}$ ) will eventually be processed in the liver [85]. Moreover, the primary mechanism for the passive accumulation of NPs in tumors is considered to result from the combination of fenestrations in the vasculature and poor lymphatic drainage from tumors [86], known as the enhanced permeability and retention (EPR) effect [87]. However, similar fenestrations in the blood vessels are a part of the normal physiology of the liver and provide the pathway to passive accumulation of NPs to the hepatic tissue [88]. Once trapped in the liver, NPs have been reported to interact with hepatocytes, liver sinusoidal endothelial cells, B cells and Kupffer cells [89]. Even NP uptake in the hepatocytes has been reported and is typically 
impacted by the NP surface charge and other chemical modifications [90,91]. As hepatocytes make up $60 \%$ of all the cells in the liver and are responsible of the metabolism and elimination of most foreign compounds, including pharmaceuticals, in vivo, understanding the NP interactions in the liver is critical to the clinical translation of nanomedicine for diagnosing and treating diseases.

If uptaken by hepatocytes, NPs may interact with the cellular content, such as the cytochrome P450 (CYP) system, prior to their elimination via the hepatobiliary route [85]. The CYP system is in charge of the phase I metabolism of majority of drugs in clinical use [92]. Although further conjugation reactions (e.g., glucuronidation) may follow CYP metabolism, the substrate specificity associated with CYPs forms a bottleneck and renders the CYP-mediated metabolic clearance most critical in respect to the safety and efficacy of medical therapies, especially in case of highly polymorphic isoforms such as CYP2D6 [93]. Moreover, CYP enzymes are membrane-bound proteins that reside on the cytosolic side of the endoplastic reticulum (ER) and are thus more liable to NP interactions compared with, e.g., the phase II uridine 5'-diphospho-glucuronosyltransferases (UGTs), which face the lumen side of the ER. Currently, several in vitro models exist for studying the hepatic drug metabolism via the CYP system, including transgenic cell lines and primary hepatocytes, liver microsomal fractions and recombinant (single) CYP isoforms expressed in insect cell (referred to as baculosome or supersome in the commercial contexts) [94,95]. Of the different available in vitro models, the subcellular preparations (microsomes, recombinant enzymes) however provide the most straightforward approach to mechanism-based interaction screening. Human liver microsomes (HLM) have become the industry standard for pre-clinical metabolic profiling and drug interaction studies because of their relative affordability and acceptable in vivo resemblance [95,96][x]. HLMs consist of vesicles of the hepatocyte ER, prepared by differential centrifugation, so as to ensure that the microsomal preparation contains all the CYP isoforms as well as the redox-partners. The recombinant microsomal human CYPs produced in the insect cells are primarily used for preliminary screening of isoform-specific interaction risks owing to their limited in vivo correlation with respect to predicting the hepatic clearance. Via protein engineering, it is also possible to manufacture soluble (not membrane-bound) human CYP isoforms by truncating the hydrophobic N-terminal membrane bound domain of CYPs [97][x]. However, this neither omits the need for the auxiliary proteins or an electron source nor provides a viable model with a view to in vivo predictions.

The research regarding CYP interactions has mainly centered around metallic NPs (silver, gold), which have been shown to alter the CYP metabolism both in vitro and in vivo [98]. In most in vitro studies, the impact of silver NPs on human and rat CYP system (assessed based on liver microsomes or recombinant enzymes) has been weak or insignificant [99-101], although moderate inhibition of 
CYP2C9, CYP2C19, and CYP3A4 activities in human liver microsomes has also been reported [99]. The impacts of gold NPs in vitro are often somewhat similar to those of silver NPs [102-104]. For example, silver NPs have been reported to cause moderate to strong inhibition of recombinant CYP1A2, CYP2C9, and CYP2C19 activities in vitro [104], whereas the gold NPs moderately inhibited recombinant CYP2C9, CYP2C19, and CYP3A4 activities, but not so much the CYP1A2 [104]. However, the in vivo interactions vary greatly depending on the NP type, size and charge, which are the critical NP properties in terms of cellular uptake. For example, almost 28 -fold increase in the CYP1A1 expression in rats in vivo was reported after a single intravenous injection of gold NPs [102]. In case of silver NPs, the strong inhibition of CYP2C and 2D activities observed in rat liver microsomes in vitro was not reproduced in vivo [101].

Generally, the risk for CYP inhibition tends to increase as a function of decreasing particle size, as has been confirmed by both gold and carboxyl polystyrene NPs [103,105]. In addition to size, the surface charge is known to alter the NP uptake by hepatic cell types due to differences in protein adsorption to the NP surface and the electrostatic interactions between the NPs and the cell membrane $[106,107]$. However, the limited data available of NP uptake in hepatocytes results in intricate in vitro-in vivo correlation with respect to the CYP inhibition. Moreover, the subcellular fractions (such as liver microsomes) commonly used in the enzyme inhibition studies in vitro are not capable of predicting the possible NP impacts on gene expression (i.e., CYP induction). Nevertheless, the determination of the NP impacts on the in vitro clearance of drugs via the CYP system could provide the preliminary tool for identification of possible hazardous NP-drug interactions. For example, the pioneering work with porous silicon based NPs reported significantly reduced activity (ca. 50-60 \% of the control, $\mathrm{p}<0.001$ ) for the highly polymorphic CYP2D6 in human liver microsomes in the presence of NPs independent of their surface chemistry or charge [108]. Besides enzyme activity ( $V_{\mathrm{MAX}}$ ), the NPs were shown to alter the enzyme affinity $\left(\mathrm{K}_{\mathrm{M}}\right)$ so that the total intrinsic clearance $\left(\mathrm{CL}_{\text {int }}\right)$ was most impacted by the alkyne-modified porous silicon NPs. Owing to the relatively large size of the porous silicon NPs used in the study (160-180 nm), competitive binding to the enzyme's active size (typically below $3 \mathrm{~nm}^{3}$ [109]) was not likely. Instead, the inhibition mechanism was concluded to be combination of noncompetitive and uncompetitive binding [108]. Considering the highly variable expression of CYP2D6 between individuals (rapid vs. slow metabolizer genotypes) [92], these preliminary in vitro findings suggest that NP interactions with the CYP system should not be neglected. Currently, the "assay cascade" for the characterization of nanomaterials, developed by the European Nanomedicine Characterisation Laboratory (EUNCL), does not include characterization of the CYP interactions, but focuses on determination of the physical and chemical properties of NPs, as well as screening of their immunological, hematological, and toxicological 
properties in vitro [110]. The microfluidic subcellular characterization techniques reviewed in the next section could provide the means for high-throughput preliminary screening of the impacts of NPs on the CYP system in vitro. Besides NP effects, the same technology readily fits for screening of drug-drug interactions under microfluidic flow, e.g., in combination with controlled release studies.

\section{Section 3.3.2 Cytochrome P450 interaction studies in through-flow conditions}

In microfluidic cell-based assays, the cells are readily adhered to the microchannel bottom strong enough that they remain "immobilized" upon application of the through-flow, if the flow-induced shear stress is tolerable. In contrast to intact cells, the use of cellular components, such the microsomes or recombinant enzymes, requires custom methodology for incorporating the enzymes into the microchannel in a permanent fashion. Once immobilized, the enzymes are compartmentalized in a confined space, which facilitates both spatial and temporal control of, e.g., NP exposure with the help of microfluidic through-flow. In enzyme kinetic characterization, the microfluidic actuation enables the creation of concentration gradients of the substrate of interest and thus determination of the kinetic constants with a single experiment [111-113]. From the analysis viewpoint, enzyme immobilization omits the need for sample purification (separation of the protein and lipid content from the analytes of interest), which facilitates online coupling of the reactor to a mass spectrometer, for example [114]. Though, this approach is applicable to NP characterization only to a limited extent. Sometimes, immobilization also enhances the stability of the enzymes toward denaturation during both storage and use. Section 3.3.2.1 gives an overview of the commonly used strategies feasible for enzyme immobilization on microfluidic devices and the special precautions that should be accounted for when establishing immobilized CYP microreactors. Section 3.3.2.2 provides additional considerations regarding the design of the microreactors and the selection of the microfabrication materials.

\section{Section 3.3.2.1 Immobilization strategies for cytochrome P450 enzymes}

The CYP system as a whole comprises of multiple membrane-bound cooperative enzymes, which places an extra challenge to the drafting of biologically relevant immobilization strategies. Besides CYP isoforms, various redox partner enzymes are required to supply electrons for the metabolism reactions, most importantly nicotinamide adenine dinucleotide phosphate-cytochrome P450 reductase (NADPH-CPR) [115,116]. In addition, the reactions will require both oxygen and NADPH as cofactors and the enzymes need to remain in their natural environment, embedded in the lipid bilayer, to maintain their activity [117]. The immobilization as well as operation conditions should 
also be gentle enough to ensure that the enzymes are not denatured during the process. For example, elevated temperatures [118], organic solvents [119] and oxygen radicals generated in CYP-mediated reactions $[120,121]$ have all been reported to promote CYP inactivation. To be able to draw clinically relevant conclusions based on the in vitro data of the immobilized enzymes, the kinetic parameters should remain unchanged compared with nonimmobilized enzymes, which complicates the use of scaffold-based immobilization techniques and incorporation of chemical modifications to the protein structures [113]. The pros and cons of the common enzyme immobilization techniques with respect to CYP immobilization are briefly discussed below. These techniques are generally divided into three main categories: Enzymes can either be (i) entrapped inside a porous matrix, (ii) cross-linked with each other to form enzyme aggregates or crystals, or (iii) bound to an inert support material via physical (adsorption) or chemical interactions (covalent or affinity-based binding) (Figure 8).

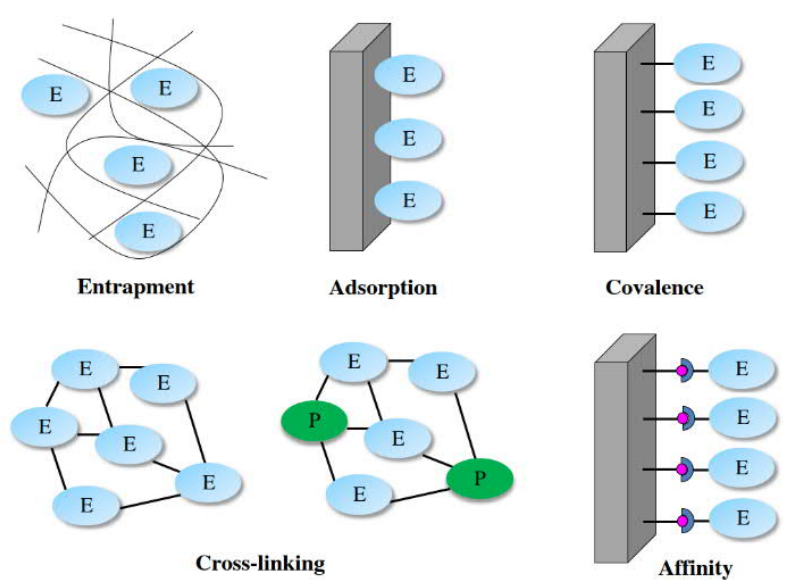

Figure 8. Schematic representation of the main different methods of enzyme immobilization. E: enzyme, P: inert protein. Republished with permission of Elsevier, from Sassolas et al. 2012 [122]; permission conveyed through Copyright Clearance Center, Inc.

With the entrapment techniques, enzymes are physically retained inside a natural or synthetic polymer matrix, which is synthetized in the presence of the enzyme. The matrix forms physical constraints that enable mechanical enzyme immobilization in high volumetric concentrations and relatively mild immobilization conditions $[123,124]$. Entrapment is thus readily feasible for immobilization of both soluble and membrane-bound enzymes, as it does not require any specific chemistry. However, the density of the matrix plays a critical role and has to be carefully optimized to avoid enzyme leaching (too loose matrix) and diffusion-limited kinetics resulting from retarded mass transfer (too dense matrix) [125].On microfluidic devices, both sol-gels [126] and hydrogels [127] have been used as matrices for enzyme entrapment, but hydrogels are often preferred because of their better transparency and biocompatibility (no toxic reagents needed for polymerization) [128]. Commonly used hydrogels include, e.g., synthetic polyethylene glycol and polyacrylamide as well as chitosan, 
agarose and other polymeric biomolecules [129]. In a pioneering work, the shelf-life of HLM (during storage) was substantially improved (weeks vs. days) as the result of sol-gel entrapment, but the enzyme affinity (testosterone to CYP3A4) was simultaneously increased compared to that of nonimmobilized enzymes [126]. The CYP activities of entrapped HLM are generally similar to those of nonimmobilized enzymes, but long-term stabilities during use are seldom reported. Besides gelbased matrices, HLMs have also been entrapped in microfluidic devices with the help of porous $(\varnothing 0.4$ $\mu \mathrm{m})$ polycarbonate membranes [130].

In contrast to scaffold-based enzyme immobilization, scaffold-free enzyme macroparticles can be prepared via crosslinking, including cross-linked enzyme crystals (CLECs) and cross-linked enzyme aggregates (CLEAs) [125,128]. CLECs are typically prepared from crystallized enzyme by the addition of a bifunctional reagent, such as glutaraldehyde, which results in stable and highly active enzyme particulates of controlled size. Compared with CLECs, crosslinking of aggregates (CLEAs) is somewhat easier and does not necessarily require as high enzyme purity. However, neither of the two techniques is very well feasible for immobilization of membrane proteins, such as mammalian CYPs, and crosslinking approaches have thus been primarily used for soluble bacterial CYPs only $[131,132]$.

The enzyme binding on support materials can be either covalent or non-covalent. Covalent binding typically relies on functional groups $\left(-\mathrm{NH}_{2}\right.$ and $\left.-\mathrm{COOH}\right)$ naturally occurring in enzymes. This often results in nonuniform orientation with respect to the active site of the immobilized enzymes, as it is difficult to control where in the amino acid chain the covalent bond will form. If the enzyme's active site is 'face down' toward the support material, the overall activity is inevitably decreased because of apparent steric hindrance. Therefore, spacer molecules, attached to the support material prior to enzyme binding, are often employed to distance the enzyme from the surface [133]. Covalent binding usually allows for a relatively stable anchorage of the enzyme to the carrier surface. However, if the charged amino acid residues are extensively employed by the covalent bonds, the enzyme's surface charge, and thus its natural conformity may change and activity decrease upon immobilization [134], although increased activities have also been reported [135]. In a prior work, CYP2C9 baculosomes were covalently bound on magnetic particles with the carbodiimide method to create a packed bed capillary reactor compatible with online capillary electrophoresis analysis [136]. Although the setup facilitated enzyme kinetic determinations in through-flow conditions, rapid activity loss of the immobilized enzyme during the measurements was reported. In most other reports, covalent binding has mainly been applied to soluble recombinant CYPs (lacking the hydrophobic N-terminus sequence) [137-139]. However, the disadvantage of soluble enzyme systems is the lack of auxiliary 
proteins (redox partners), which need to be separately introduced along with the through-flow [137] or immobilized onto the same carrier. Adjusting the stoichiometric ratios and the spatial relationships of the different redox proteins is however technically and economically challenging. Moreover, with respect to in vitro-in vivo extrapolation, the immobilized enzymes should ideally maintain their physiology unchanged, which reduces the biological significance of the in vitro data derived from soluble (not membrane-bound) enzymes.

The non-covalent methods (Figure 8) can be divided into physical (hydrophobic and van der Waals interactions), ionic (electrostatic interactions), and affinity-based (e.g. antibody-mediated binding) methods $[125,134]$. Weak noncovalent interactions do not usually alter the tertiary structure of the enzymes as much as covalent binding, which helps the enzymes to retain their natural activity [140]. However, the non-covalently bound enzymes are easily washed away from the carrier surface, especially at elevated temperatures, owing to their low binding energies compared with covalent binding [125,134]. An exception is affinity-based biotin-avidin binding, which has been exploited to immobilize recombinant CYPs by incorporating biotin tag to the protein structure and binding the biotinylated CYPs on avidin-coated chromatography column [141]. However, this approach too required chemical modification of the protein structure, which resulted in loss of the enzyme activity at physiological temperatures. In another work [142], biotin-containing, unilamellar fusogenic liposomes were employed to transfer the biotin tag to the HLM membrane (Figure 9), which is substantially less laborious and more universal protocol compared with biotin-labeling of the protein structure [141]. By modifying the lipid membrane instead of the protein structure, the overall immobilization process was gentle enough that the enzyme kinetic parameters remained similar to those of nonimmobilized enzymes [142]. Besides fusogenic liposomes, artificial lipid bilayers prepared on solid supports have also been employed to immobilize microsomal vesicles via membrane fusion [143]. 


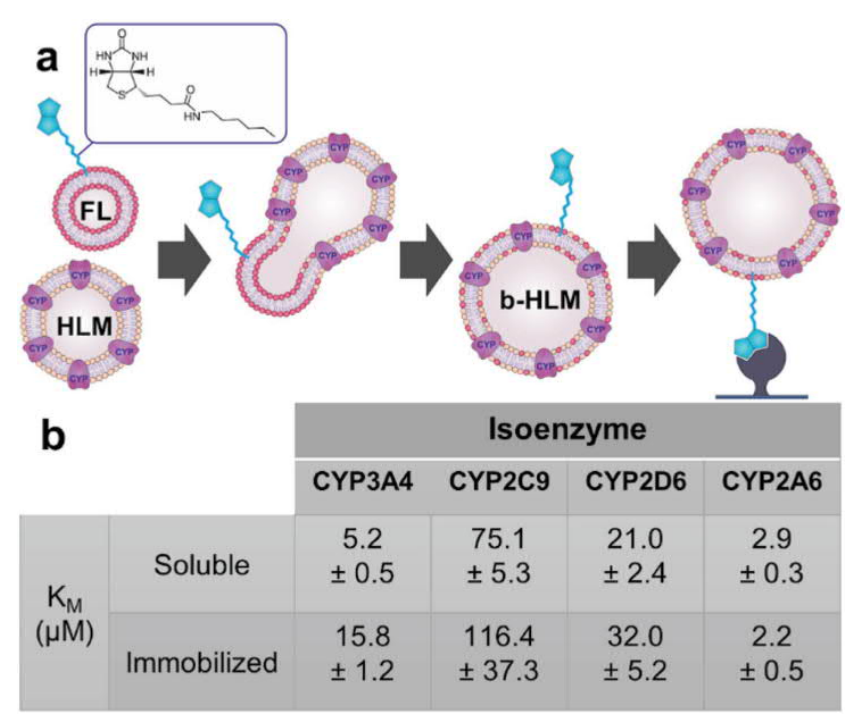

Figure 9. Immobilization of human liver microsomes (HLM) on streptavidin-functionalized magnetic particles with the help of fusogenic liposomes. a) A schematic describing the membrane fusion between biotin-containing fusogenic liposomes and HLM resulting in biotinylated HLM. b) Isoenzyme-specific $\mathrm{K}_{\mathrm{M}}$ values ( \pm standard error) of four main CYPs for immobilized and nonimmobilized (soluble) HLMs. Republished with permission of John Wiley and Sons, from Kiiski et al. 2019 [142]; permission conveyed through Copyright Clearance Center, Inc.

\section{Section 3.3.2.2 Microfabrication materials and design considerations}

In addition to enzyme activity and stability, implementation of microfluidic immobilized enzyme reactors necessitates careful selection of proper microfabrication materials as well as mindful design of the through-flow reaction chamber. Integration of scaffold-based immobilization matrices with a microfluidic network is relatively straightforward. For example, polyethylene glycol based hydrogels can be microstructured in situ (through the microchannel cover layer) by UV lithography, provided the covering layer is transparent to the chosen wavelengths [127]. But as the scaffold-based systems suffer from retarded diffusion, direct binding of enzymes on a solid support material is practically the better choice for enzyme kinetic determinations. However, functionalization of mere microchannel walls rarely enables immobilization of high enough amount of enzymes to produce detectable amounts of metabolites for deriving the kinetic parameters. The total surface area (per volume) available for enzyme binding is typically increased by "packing" the microreactor with, e.g., microbeads [136,137] or porous polymer monoliths [144,145] (Figure 10). Microstructured pillar arrays similar to those in Figure 2 in Section 3.1 can also be used to increase the total surface area $[142,146,147]$. 
(a) Wall-coated type channel

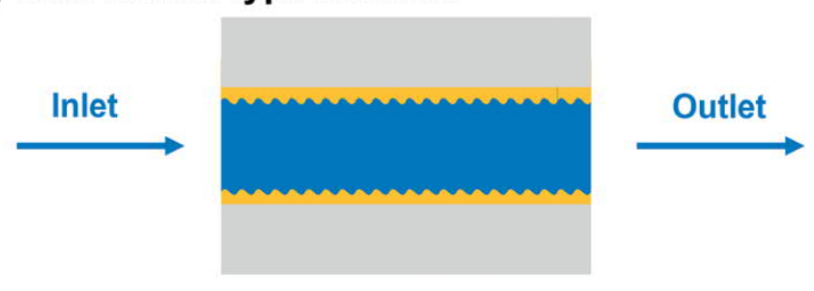

(b) Packed-bed type channel

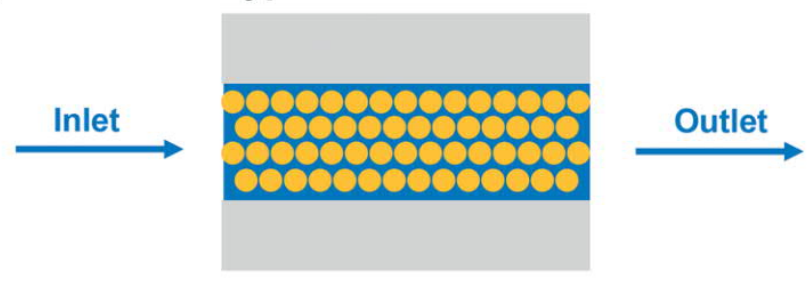

(c) Monolithic type channel

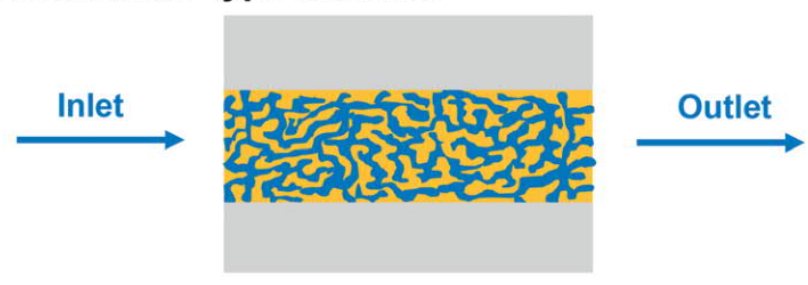

Figure 10. Typical designs for increasing the surface-to-volume ratio of microfluidic channels: (a) wall-coated type channel, (b) packed-bed type channel and (c) monolithic type channel. Republished with permission of the Royal Society of Chemistry, from Zhu et al. 2020 [148]; permission conveyed through Copyright Clearance Center, Inc.

Microchannel packing with beads is relatively straightforward: The beads can be introduced into the channel by injecting and retained with the help of magnetic field (in case of magnetic microbeads [149]) or microfabricated frit structures (Figure 11a). There is also a wide range of commercially available microbeads with different surface chemistries for both affinity-based and covalent binding of enzymes. However, tight microbead packings easily increase the back pressure in the microfluidic system and thus necessitate strong bonding between the microchannel bottom and cover layers, rendering for instance PDMS hardly feasible for packed bed applications. In situ curing of porous polymer monoliths by UV (through the microchannel cover layer) or heating, in the presence of porogens, is also a relatively straightforward process, which only requires UV transparent or thermally stable microfabrication materials. Compared with microbead-based packings, the porous polymer monoliths typically show lower back pressures and do not require mechanical frit structures as there is no risk of solid phase escape similar to that of packed beads [150,151]. However, controlling the pore size uniformity and the homogeneity of the packed bed may be challenging. Especially seamless anchoring of the monolith to the microchannel surfaces is often difficult and gives rise to void volumes at the sharp corners and microchannel edges unless special anchoring 
chemistry is applied (Figure 11b) [152]. More importantly, both microbead-based packings and porous polymer monoliths may retard the mass transfer into and out of the immobilized enzymes similar to the scaffold-based immobilization matrices. As the result, the micropillar arrays often appear as the most feasible "packing" strategy for enzyme kinetic determinations, especially in the context of NP characterization.

(a)

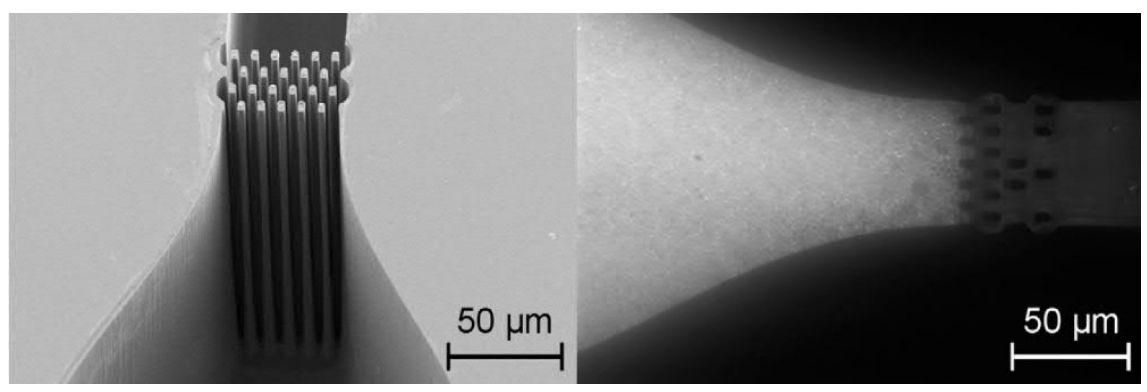

(b)

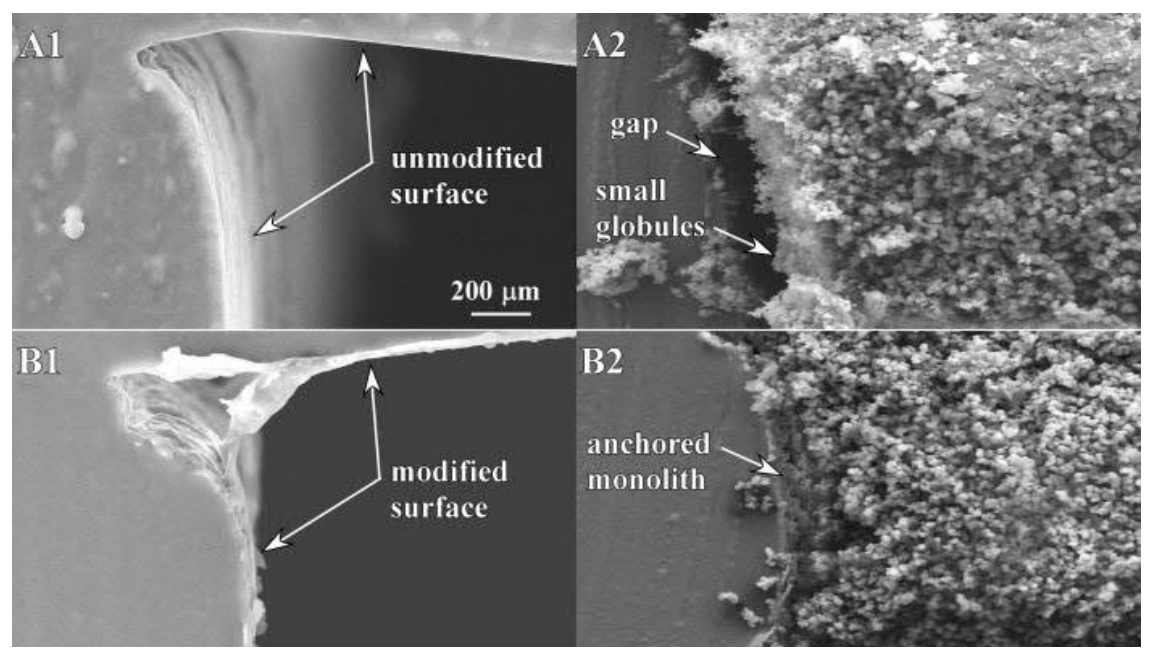

Figure 11. (a) Scanning electron micrograph of microfabricated frit structures (left) acting as a mechanical barrier to retain fluorescent microbeads injected into a microfluidic channel (right, topview). Republished with permission of Elsevier, from Haapala et al. 2010 [153]; permission conveyed through Copyright Clearance Center, Inc. (b) Methacrylate-based porous polymer monoliths cured in situ in an unmodified (A1, A2) and modified (B1, B2) PDMS microchannel illustrating the void volume next to the microchannel wall (A2) if anchoring of the polymer monolith is deficient. Republished with permission of AIP Publishing, from Burke and Smela 2012 [152]; permission conveyed through Copyright Clearance Center, Inc.

Ordered micropillar arrays can be made with high precision from silicon by anisotropic etching [147,154] or from polymer photoresists by direct UV lithography [155]. The lithographically defined micropillar arrays may also act as master molds for replicating the structures into other UV and heat curable polymers or thermoplasts, as described in Section 3.1, although the achievable aspect ratios of replicated pillars may be limited compared with direct microfabrication techniques [18]. Although 
silicon (oxide) readily facilitates a multitude of surface reactions, especially the possibility to use replication techniques increases the freedom in material selection with a view to enzyme immobilization on micropillar surfaces. Thus, from the material perspective, many different chemistries are available for enzyme immobilization, but they all have their specific requirements in terms of, e.g., pH, temperature, and applicable solvents, which need to match with the properties of the fabrication material [156]. For example, PDMS has very limited solvent compatibility as it tends absorb the solvent molecules and swell upon exposure [157]. PDMS is also inherently hydrophobic and relatively inert, which complicates its chemical surface modification [158,159]. Typically, some kind of chemical surface modification, i.e., covalent coupling of appropriate linker molecule, is a prerequisite for enzyme immobilization directly on micropillar surfaces, although some polymer surfaces readily contain functional groups. For example, the OSTE polymers feature either free surface thiols or allyl groups, the density of which can be tuned by simply manipulating the molar ratio of the thiol and allyl monomers in the bulk composition [20]. Especially the free thiol groups of the OSTEs have been extensively employed in a variety of microfluidic immobilized enzyme reactors making use of, e.g., photopolymerization [142,160] or gold nanoparticle interaction with the free thiol residues on both the chip surface and in the protein structure [18]. Besides surface chemistry, attention should be paid on the possible nonspecific interactions between the polymers and the biomolecules to ensure that the catalytic activity is not lost because of protein fouling. Many commonly used polymers, including PDMS, tend to adsorb biomolecules [159]. A common solution is to functionalize the surface with polyethylene glycol, which not only reduces the non-specific binding [161][x], but may also increase the enzyme activity via the reduction of steric constraints and stabilization of the protein structure [162]. To certain degree, the non-specific binding may also be prevented by oxygen plasma treatment [163,164], although the impact is typically reversible. Sometimes, the plasma treatment may however give rise to newly formed functional groups, which may then be used for further chemical coupling reactions [165].

From the design perspective, the primary benefits of microstructured pillar arrays over other packing strategies include the possibility to adjust and control the total surface area in a reproducible manner, which is critical to be able to quantitate the amount of the bound enzyme. Furthermore, by adjusting the geometry and dimensions of the micropillars (diameter, spacing), the surface-to-volume ratio may also be optimized so as to avoid diffusion-limited kinetics and to maximize the amount of the immobilized enzyme. The ordered micropillar arrays also support capillary filling [154] and reduce pressure differences within the microchannel. In addition to the amount of immobilized enzyme, the microchannel design impacts the enzymatic reaction time, which is equal to the residence time of the target components inside the microfluidic device. Besides flow rate (linear velocity), the residence 
time can be adjusted by manipulating the microchannel dimensions (width, length) as illustrated in Figure 12. Under optimized conditions, the metabolic activity should be stable over time and, in case of CYP enzymes, often dependent on the reaction temperature, as illustrated in Figure 13. To maintain physiological temperature, the microreactors may be placed in an incubator, on a hot plate or on an external resistive heater element. In addition, microfabricated resistive heater elements may also be integrated with the microfluidic channels via thin-film metallization. Besides temperature control, mixing of the reagents may be necessary for creating the concentration gradients over time. For comprehensive review of the heating and mixing possibilities on microfluidic devices, the reader is advised to familiarize with relevant prior reviews $[166,167]$.



Single-channel (b)



Serpentine-channel (c)

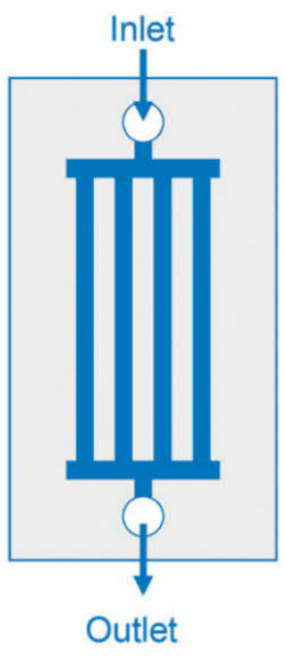

Multi-channel (d)

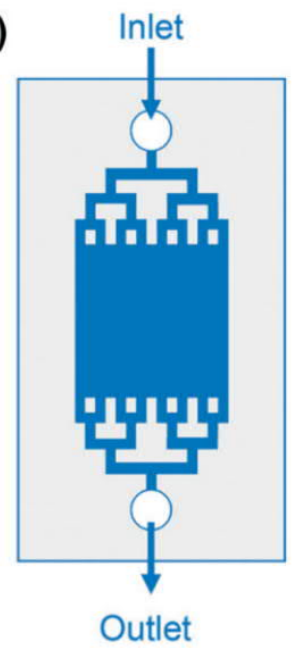

Planar chamber

Figure 12. Representative configuration designs of microfluidic chips that can be used for adjusting the residence time: (a) single-channel chip, (b) serpentine-channel chip, (c) multi-channel chip and (d) planar chamber chip. Republished with permission of the Royal Society of Chemistry, from Zhu et al. 2020 [148]; permission conveyed through Copyright Clearance Center, Inc. 


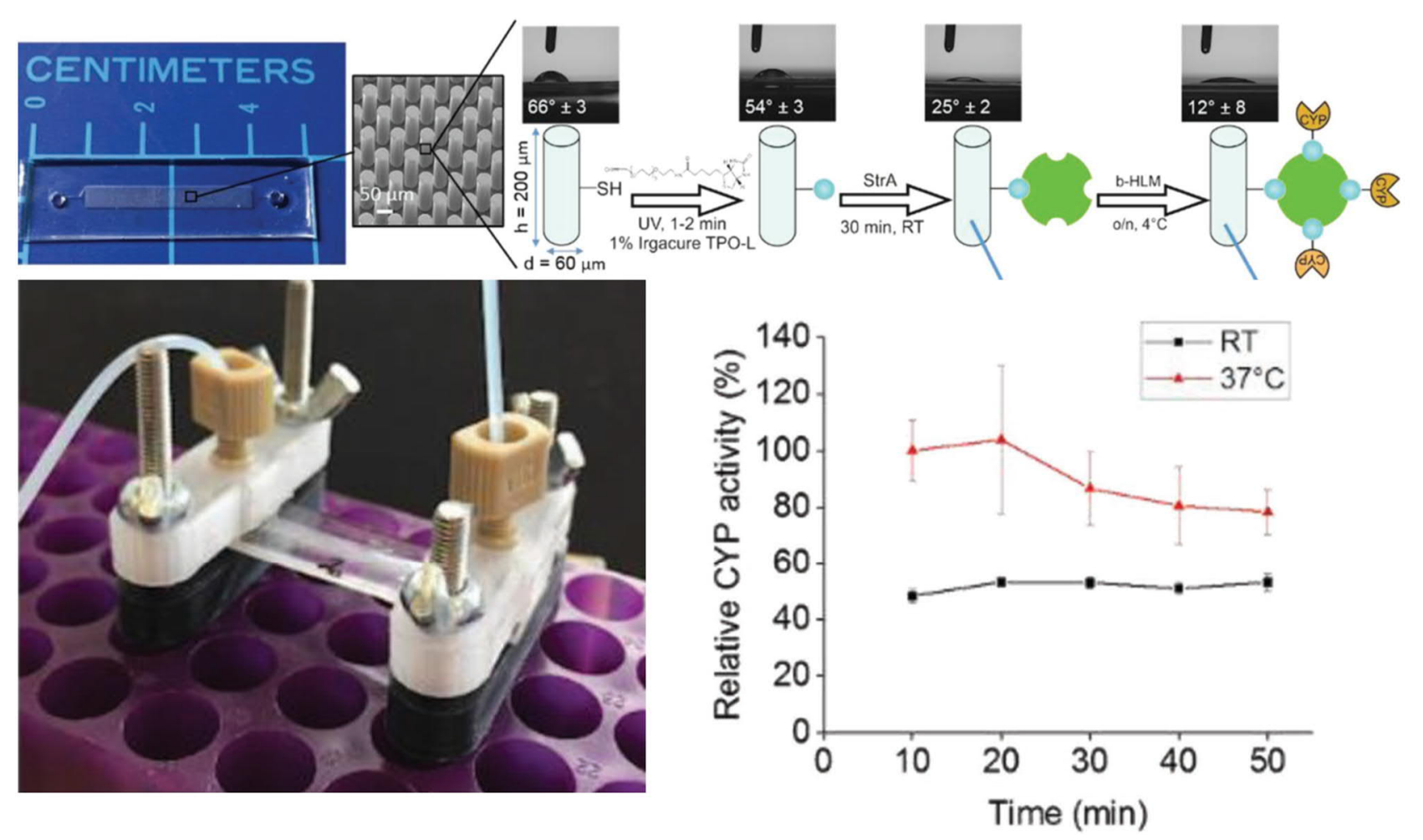

Figure 13. Top: A micropillar-based immobilized enzyme reactor made from OSTE polymers by replication techniques and functionalized with biotin-alkyne by photopolymerization and streptavidin via biotin-avidin binding, prior to immobilization of biotinylated HLM to the streptavidin surface. Left: Photograph of the microfluidic setup. Right: Stability of the CYP activity over time on the OSTE reactor. Republished with permission of John Wiley and Sons, from Kiiski et al. 2019 [142]; permission conveyed through Copyright Clearance Center, Inc.

\section{Section 3.4 Microfluidic total analysis systems}

This section provides a brief overview of the future prospects regarding system level integration possibilities facilitated by microfabrication of miniaturized separation and sample preparation systems as integral parts of the microfluidic in vitro models. Here, the focus will be on microfluidic total chemical analysis systems feasible for characterization of the impacts of nanomedicine on, e.g., cell metabolism or drug elimination on a molecular level, rather than characterization of the properties of pharmaceutical nano- and microsystems. Besides molecular chemical analysis, a wealth of microfluidic techniques have also been developed for various particle sorting needs [168], but these techniques are typically applicable to micrometer-sized particles only. However, somewhat similar approaches and techniques can be used for cell separation and sorting on microfluidic devices [169], which may appear useful for the characterization of the impacts of nanomedicine in selected cases. Regarding chemical analysis with the help of microfluidic devices, the separation systems reviewed below represent the gold standard techniques originally established to speed up the analysis of small 
organic molecules, peptides, and proteins in biological and synthetic matrices. To date, these techniques have hardly been applied to characterization of nanomedicine and therefore this section provides only a brief discussion of the main available techniques and their current technology readiness level, which sets the framework for their possible future use in the context of nanomedicine characterization. Comprehensive reviews of the feasibility of these techniques to metabolomics, proteomics, and other clinical and forensic applications can be found elsewhere [2,170,171].

\section{Section 3.4.1 Microfluidic separation systems}

The entire evolution of microfluidic total analysis systems (a.k.a. lab-on-a-chip) originates from the pioneering works in early 1990's, which set the theoretical frame and experimental evidence for rapid chemical sensing on a microfabricated, planar glass chip by a technique called microchip capillary (zone) electrophoresis [8,9]. This technique has since became the gold standard for microfluidic separations and also transferred to practically any available microfabrication material. In microchip electrophoresis, the sample solution is introduced into a microfabricated separation channel via an intersecting side (injection) channel (Figure 14a) [172]. Compared with conventional capillary-based electrophoresis, the initial sample plug is much narrower [173], which enables significantly short separation times (at best < $1 \mathrm{~min}$ ) under high electric field. As the result, the length of the separation column can be decreased (from ca. $1 \mathrm{~m}$ to only a few centimeters) and much lower separation voltages can be used on a microfluidic device to reach the same electric field strength (volts per meter), which is the critical parameter in terms of the resolving power. From the materials perspective, the only requirements are that the microchannel surfaces are charged and do not non-specifically adsorb the target analytes. In practice, most microfabrication materials maintain cathodic electroosmosis, even if the bulk composition does not contain any functional groups. According to a theory, the apparent negative surface charge may originate from adsorption of hydroxyl ions to the microchannel surfaces [174]. Instead, non-specific adsorption (biomolecule fouling) is a pronounced problem with many polymer materials, especially PDMS, which often needs to be coated to avoid surface interactions [175]. However, inherently biofouling-resistant materials also exist, such as the lithographically defined organically modified ceramics [176]. 
(a)
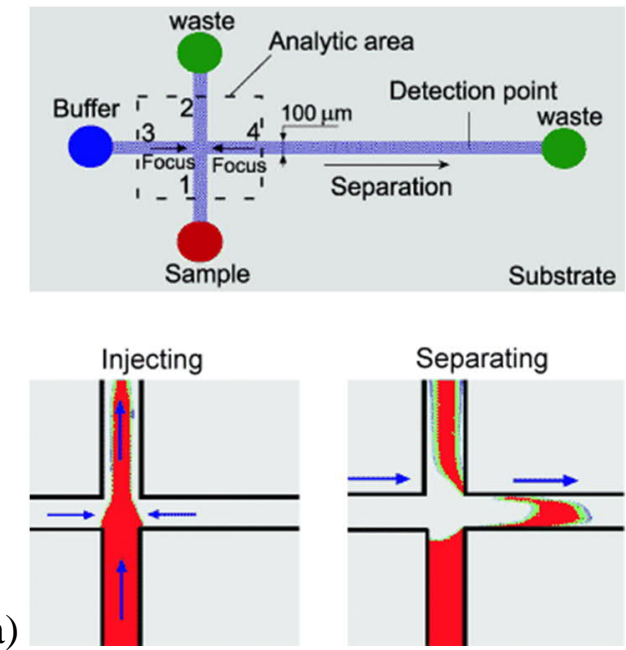

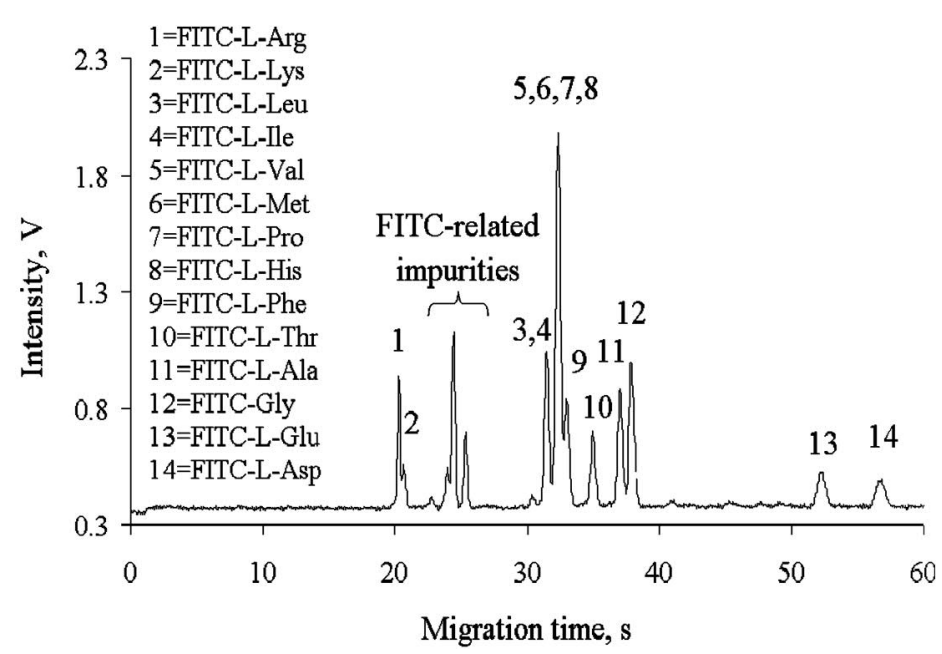

\section{Gated sample injection}

(c)



(d)
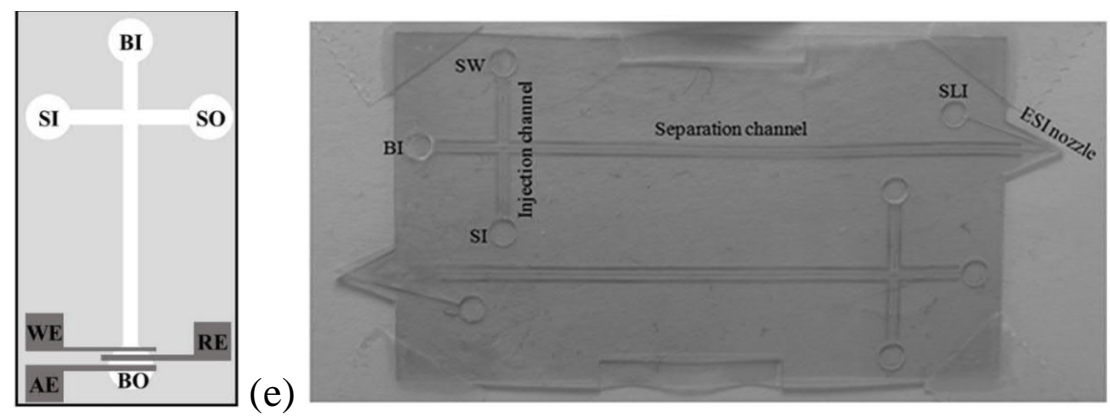

Figure 14. (a) Sample loading and dispensing steps on a microchip electrophoresis device. Republished with permission of Springer Nature, from Fu and Tsai 2008 [177]; permission conveyed through Copyright Clearance Center, Inc. (b) An example of electrophoretic separation of fluorescent derivatized amino acids on a microchip made of organically modified ceramics. Republished with permission of the American Chemical Society, from Sikanen et al. 2010 [25]; permission conveyed through Copyright Clearance Center, Inc. (c) Experimental arrangement of microchip electrophoresis in combination with fluorescence detection. Republished with permission of Elsevier, from Kim et al. 2005 [178]; permission conveyed through Copyright Clearance Center, Inc. (d) Photograph and schematic view of a commercial electrophoresis chip featuring platinum electrodes for amperometric detection.

$\mathrm{BI} / \mathrm{BO}=$ buffer inlet/outlet. $\mathrm{SI} / \mathrm{SO}=$ sample inlet/outlet. $\mathrm{WE} / \mathrm{RE} / \mathrm{AE}=$ working/reference/auxiliary electrode. Republished with permission of Springer Nature, from Ollikainen et al. 2019 [179]; under the terms of the Creative Commons Attribution 4.0 
International License. (e) An SU-8-based electrophoresis chip featuring an integrated, sharp opening at the microchannel outlet for electrospray ionization mass spectrometry. BI=buffer inlet. $\mathrm{SI} / \mathrm{SO}=$ sample inlet/outlet. SLI=sheath liquid inlet. Republished with permission of John Wiley and Sons, from Nordman et al. 2010 [180]; permission conveyed through Copyright Clearance Center, Inc.

In a classical setup, the electrophoresis chip is interfaced with a standard epifluorescence microscope to facilitate monitoring of the fluorescence signal over time perpendicular to the separation channel (Figure 14c). As the microchannel heights are typically in the range of few tens of micrometers only, the optical path length on microfluidic devices is significantly short and optical absorbance detection thus often compromised. Via thin-film metallization, it is also possible to integrate electrodes to the microchannel bottom layer [181] so as to enable electrochemical detection of the separated sample components at the end of the separation channel (Figure 14d). However, metal adhesion to the bottom layer, especially in case of polymer devices as discussed in Section 3.2.1, as well as sealing of the metallized microstructures may pose additional challenges to microfabrication of electrochemical sensor chips [53]. Alternatively, the separation channel outlet can be left open to allow transfer of the separated components (in liquid phase) into gas phase ions with the help of electrospray ionization (Figure 14e). In this manner, the microfluidic separation devices may also be interfaced with mass spectrometric (MS) detection. The stability of the electrospray ionization (gas-phase transition), and thus the quality of the MS signal, benefits from a sharp-pointed, overhanging emitter tip structure, which is however challenging to achieve by most microfabrication methods [182]. An alternative approach is to attach an external emitter needle or capillary tip at the microchannel outlet. Besides laborious, this technique is however prone to dead volume generation at the junction point, which may result in loss of the achieved separation. For a more comprehensive overview of the possibilities and limitations of the microfluidics interfacing to MS, the reader is advised to familiarize with the indicated reviews [182,183]. Although microchip electrophoresis appears as a very powerful separation technique, a considerable technology barrier exists in the translation of the laboratoryscale methodologies from engineers into commercial or clinical benefit by biologists and pharmacologists. To large degree, this is because of lack of standardization of both the components and the techniques, which inevitably decreases the level of automation and thus usability of the technology in routine analysis. As the result, most of the previous literature centers around proof-ofconcept research, and only in limited cases, the technologies are thoroughly validated for their intended purpose with authentic samples and datasets [179]. 
In addition to microchip electrophoresis, a variety of miniaturized liquid chromatographic (LC) separation devices have also been developed [184,185] and some even commercialized. The detection possibilities in microchip LC are similar to those of electrophoresis chips, although most are interfaced with MS detection. The packing strategies applicable to incorporation of the stationary phase in the microchannels are practically the same as those used for immobilized enzyme reactors, including microbead-based packings, porous polymer monoliths, and microfabricated pillar arrays, typically functionalized with C18 solid phase [184,185]. Overall, the technology readiness level of microchip LC is closer to commercial level than that of microchip electrophoresis, although in most designs only the chromatographic column and the ion source facilitating MS detection are integrated on chip. Very few designs have been reported, where also the micropumps (for actuation) and sample loading would have been implemented to a single chip similarly as in Figure 15.
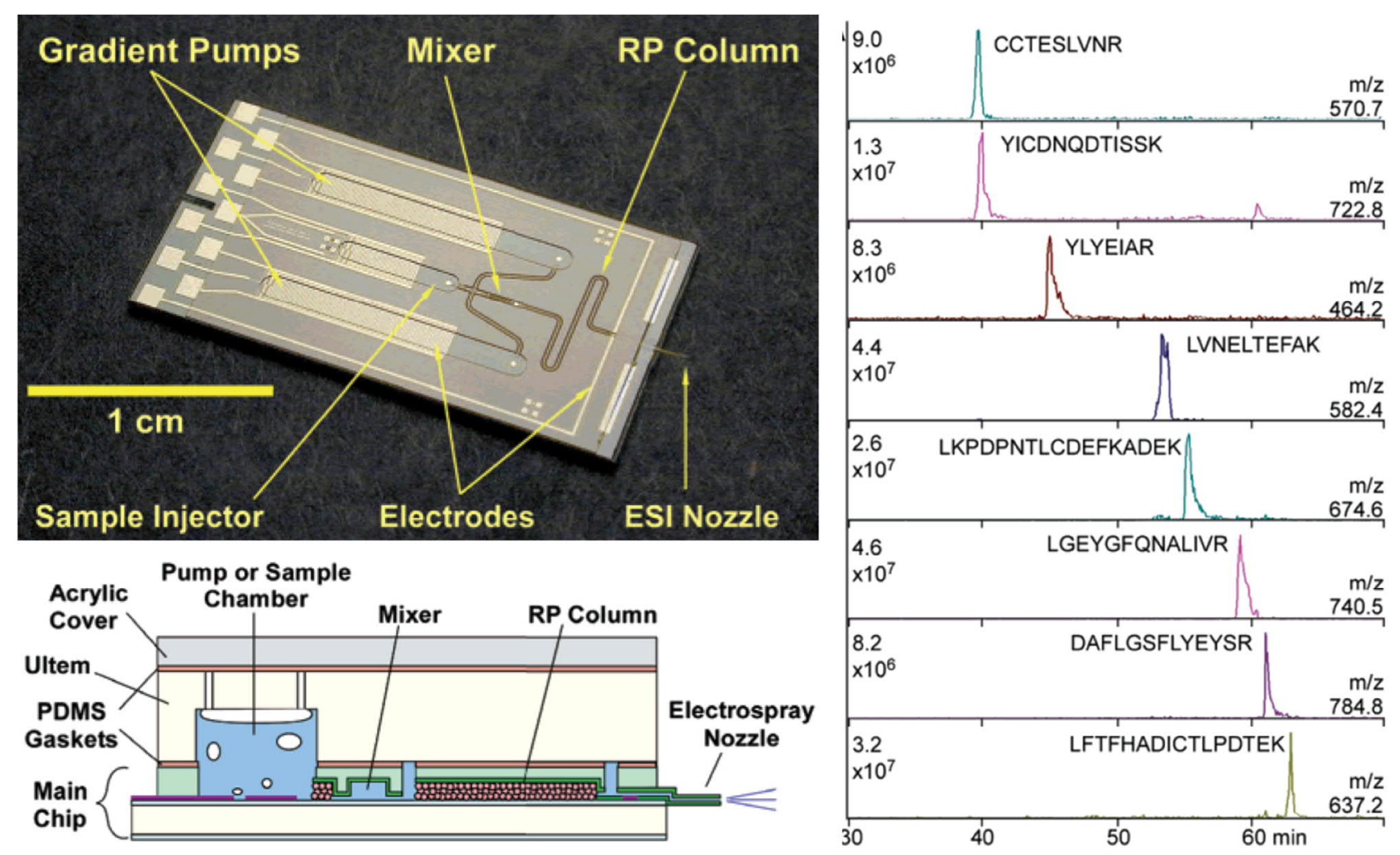

Figure 15. Left: Photograph (top) and schematic side view (bottom) of a LC chip featuring integrated, electrochemical micropumps, a micromixer, a sample injector, reversed phase chromatographic column, and an electrospray ionization nozzle. Right: Separation of eight tryptic peptides of bovine serum albumin performed using the LC chip. Republished with permission of the American Chemical Society, from Xie et al. 2005 [186]; permission conveyed through Copyright Clearance Center, Inc. 


\section{Section 3.4.2 Toward n-in-one analytical platforms}

Since 1990's, the feasibility of microfluidic separation devices has been well-established for a variety of pharmaceutically and biologically relevant analytical tasks, including analysis of cell metabolites, drugs and their metabolites, peptides and proteins $[2,170,171]$. Besides separation systems, a range of electrokinetic [187], solid phase extraction [188] and affinity-based sample preparation techniques have also been transferred on microfluidic devices to facilitate online enrichment and purification of the target analytes prior to their analysis. Although complete integration of all possible operations on a single chip is not yet a reality (in routine use), one of the key drivers of biologically inspired microfluidics is nevertheless the possibility to combine two or more microfluidic operations in sequence or in parallel - so as to improve the efficiency of analysis or to simulate the interplay between selected model organs in a systemic fashion in vitro. A classical example of an integrated microfluidic device, applied to drug cytotoxicity screening and featuring multiple parallel units for sequential cell culturing, sample preparation, and MS detection, is presented in Figure 16. Another somewhat similar concept combined immobilized enzyme reactors (HLM entrapped in polyethylene glycol), microfluidic culture of human hepatocellular carcinoma cells, and an integrated solid-phase extraction (SPE) unit with online MS analysis to study the cytotoxicity associated with drug metabolites [189]. Overall, majority of the previous literature centers around n-in-one pressure-driven analytical platforms, whereas integration of the molecular separation systems with the in vitro models is still rare. At least in part, this is due to certain technical requirements of microchip electrophoresis and LC configurations (i.e., high voltages and high pressures, respectively), which complicate their seamless integration with, e.g., cell-based assays. From this perspective, increasing interest toward modular microfluidics may pave the way for true lab-on-a-chip. 


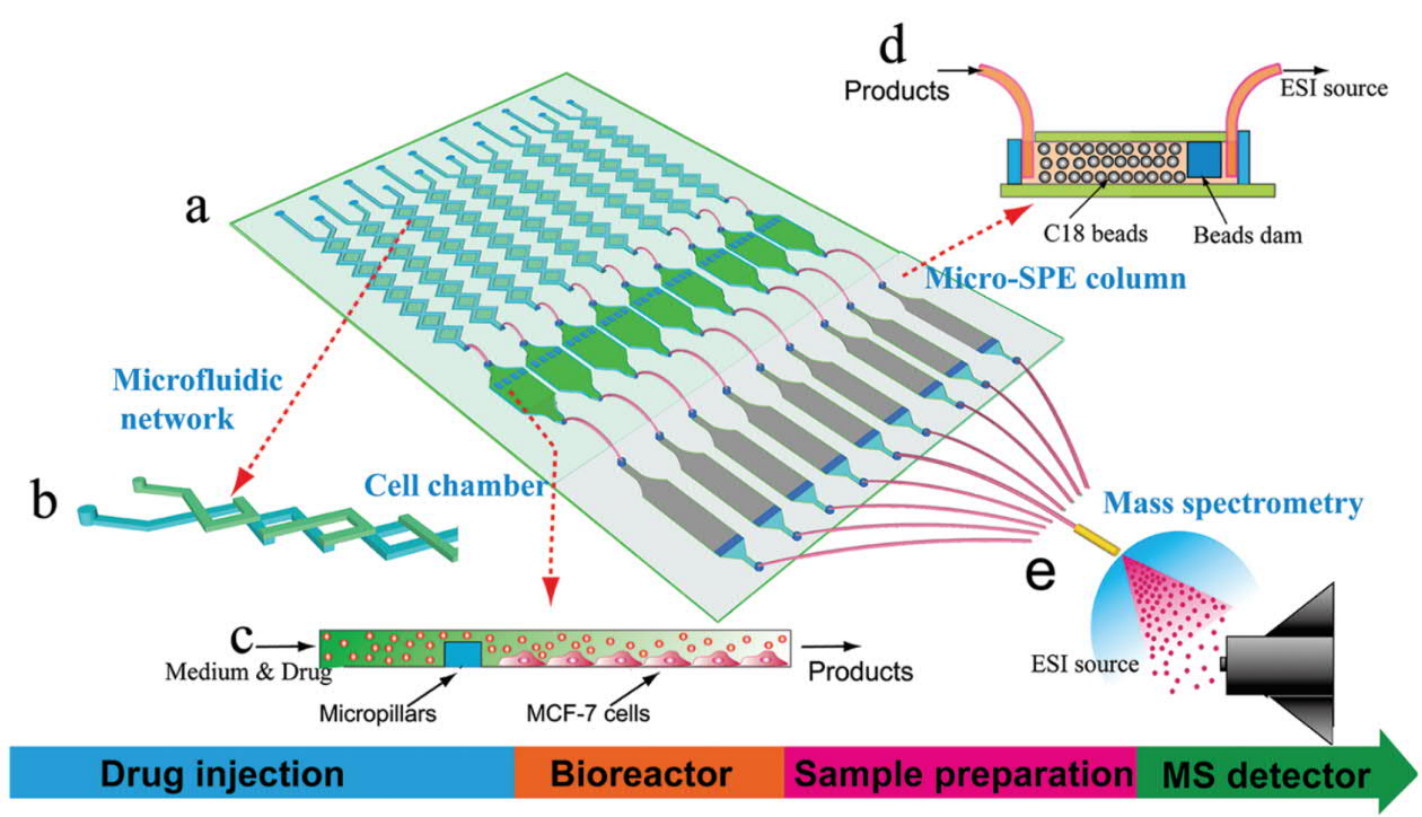

Figure 16. Schematic diagram of the chip-ESI-MS system. (a) The system consists of a microfluidic network for culture medium and drug injections, cell culture chambers, on-chip micro-SPE columns for sample desalting and purifying, and an ESI-Q-TOF-MS. (b) Microfluidic network design for the concentration gradient generator during cell culture and drug screening. (c) Magnified view of the MCF-7 cells culture chamber for cell metabolism on the microfluidic chip. (d) Magnified view of an integrated micro-SPE column on the microdevice for sample pretreatment prior to ESI-MS detection. (e) The ESI source was coupled with the micro-SPE column together by capillaries. Republished with permission of the American Chemical Society, from Chen t al. 2005 [190]; permission conveyed through Copyright Clearance Center, Inc.

\section{Section 3.5 Epilogue}

To date, a wealth of microfluidic platforms have been developed that facilitate detailed in vitro analysis of biological pathways on organ, cell and molecular levels. As the technology readiness level and automation increases, the integrated 'body-on-a-chip' platforms will become a viable and biologically relevant in vitro model for preclinical drug testing, thus reducing the need for laboratory animals and improving the quality of in vitro-in vivo predictions. By using a microfluidic platform that connects multiple engineered tissues from different organs, it is possible to replicate human organ interactions for weeks at a time, allowing us to measure the systemic drug effects on different parts of the body. Thereby, microfluidics may also pave the way to increased translation of nanomedicine into clinical use, for instance, by improving the prediction of NP targeting to the desired tissue already in the in vitro phase. The aim of this chapter was to bring the reader near to the relevant literature by highlighting three application areas most relevant to characterization of pharmaceutical nano- and microsystems. 


\section{Chapter 3}

\section{References}

1. Kang, L., Chung, B.G., Langer, R., and Khademhosseini, A. (2008) Microfluidics for drug discovery and development: From target selection to product lifecycle management. Drug Discov. Today, 13 (1), 1-13.

2. Verpoorte, E. (2002) Microfluidic chips for clinical and forensic analysis. Electrophoresis, $\mathbf{2 3}$ (5), 677-712.

3. Reyes, D.R., Iossifidis, D., Auroux, P.-A., and Manz, A. (2002) Micro Total Analysis Systems. 1. Introduction, Theory, and Technology. Anal. Chem., 74 (12), 2623-2636.

4. Auroux, P.-A., Iossifidis, D., Reyes, D.R., and Manz, A. (2002) Micro Total Analysis Systems. 2. Analytical Standard Operations and Applications. Anal. Chem., 74 (12), 26372652.

5. Patabadige, D.E.W., Jia, S., Sibbitts, J., Sadeghi, J., Sellens, K., and Culbertson, C.T. (2016) Micro Total Analysis Systems: Fundamental Advances and Applications. Anal. Chem., 88 (1), 320-338.

6. Ahn, J., Ko, J., Lee, S., Yu, J., Kim, Y., and Jeon, N.L. (2018) Microfluidics in nanoparticle drug delivery; From synthesis to pre-clinical screening. Adv. Drug Deliv. Rev., 128, 29-53.

7. Santos, H.A., Liu, D., and Zhang, H. (eds.) (2018) Microfluidics for Pharmaceutical Applications - 1st Edition, Elsevier.

8. Manz, A., Graber, N., and Widmer, H.M. (1990) Miniaturized total chemical analysis systems: A novel concept for chemical sensing. Sens. Actuators B, 1 (1), 244-248.

9. Harrison, D.Jed., Manz, Andreas., Fan, Zhonghui., Luedi, Hans., and Widmer, H.Michael. (1992) Capillary electrophoresis and sample injection systems integrated on a planar glass chip. Anal. Chem., 64 (17), 1926-1932.

10. Terry, S.C., Jerman, J.H., and Angell, J.B. (1979) A gas chromatographic air analyzer fabricated on a silicon wafer. IEEE Trans. Electron Dev., 26 (12), 1880-1886.

11. Iliescu, C., Taylor, H., Avram, M., Miao, J., and Franssila, S. (2012) A practical guide for the fabrication of microfluidic devices using glass and silicon. Biomicrofluidics, 6 (1), 165051650516.

12. Duffy, D.C., McDonald, J.C., Schueller, O.J.A., and Whitesides, G.M. (1998) Rapid Prototyping of Microfluidic Systems in Poly(dimethylsiloxane). Anal. Chem., 70 (23), 49744984.

13. Xia, Y., and Whitesides, G.M. (1998) Soft Lithography. Annual Rev. Mater. Sci, 28 (1), 153184.

14. Tuomikoski, S., and Franssila, S. (2005) Free-standing SU-8 microfluidic chips by adhesive bonding and release etching. Sensors Act. A, 120 (2), 408-415.

15. Sikanen, T., Heikkilä, L., Tuomikoski, S., Ketola, R.A., Kostiainen, R., Franssila, S., and Kotiaho, T. (2007) Performance of SU-8 Microchips as Separation Devices and Comparison with Glass Microchips. Anal. Chem., 79 (16), 6255-6263.

16. Eddings, M.A., Johnson, M.A., and Gale, B.K. (2008) Determining the optimal PDMS-PDMS bonding technique for microfluidic devices. J. Micromech. Microeng., 18 (6), 067001.

17. Huikko, K., Östman, P., Grigoras, K., Tuomikoski, S., Tiainen, V.-M., Soininen, A., Puolanne, K., Manz, A., Franssila, S., Kostiainen, R., and Kotiaho, T. (2003) Poly(dimethylsiloxane) electrospray devices fabricated with diamond-like carbon-poly(dimethylsiloxane) coated SU-8 masters. Lab Chip, 3 (2), 67-72.

18. Tähkä, S., Sarfraz, J., Urvas, L., Provenzani, R., Wiedmer, S.K., Peltonen, J., Jokinen, V., and Sikanen, T. (2019) Immobilization of proteolytic enzymes on replica-molded thiol-ene micropillar reactors via thiol-gold interaction. Anal Bioanal Chem, 411 (11), 2339-2349.

19. Sikanen, T.M., Lafleur, J.P., Moilanen, M.-E., Zhuang, G., Jensen, T.G., and Kutter, J.P. (2013) Fabrication and bonding of thiol-ene-based microfluidic devices. J Micromech. Microeng., 23 (3), 037002. 
20. Carlborg, C.F., Haraldsson, T., Öberg, K., Malkoch, M., and Wijngaart, W. van der (2011) Beyond PDMS: off-stoichiometry thiol-ene (OSTE) based soft lithography for rapid prototyping of microfluidic devices. Lab Chip, 11 (18), 3136-3147.

21. Tähkä, S.M., Bonabi, A., Nordberg, M.-E., Kanerva, M., Jokinen, Ville.P., and Sikanen, T.M. (2015) Thiol-ene microfluidic devices for microchip electrophoresis: Effects of curing conditions and monomer composition on surface properties. J. Chromatogr. A, 1426, 233-240.

22. Tähkä, S.M., Bonabi, A., Jokinen, V.P., and Sikanen, T.M. (2017) Aqueous and non-aqueous microchip electrophoresis with on-chip electrospray ionization mass spectrometry on replicamolded thiol-ene microfluidic devices. J. Chromatogr. A, 1496, 150-156.

23. Becker, H., and Gärtner, C. (2008) Polymer microfabrication technologies for microfluidic systems. Anal Bioanal Chem, 390 (1), 89-111.

24. Tsao, C.-W., and DeVoe, D.L. (2009) Bonding of thermoplastic polymer microfluidics. Microfluid Nanofluid, 6 (1), 1-16.

25. Sikanen, T., Aura, S., Heikkilä, L., Kotiaho, T., Franssila, S., and Kostiainen, R. (2010) Hybrid Ceramic Polymers: New, Nonbiofouling, and Optically Transparent Materials for Microfluidics. Anal. Chem., 82 (9), 3874-3882.

26. Bonabi, A., Cito, S., Tammela, P., Jokinen, V., and Sikanen, T. (2017) Fabrication of concave micromirrors for single cell imaging via controlled over-exposure of organically modified ceramics in single step lithography. Biomicrofluidics, 11 (3).

27. Weisgrab, G., Ovsianikov, A., and Costa, P.F. (2019) Functional 3D Printing for Microfluidic Chips. Adv. Mater. Technol., 4 (10), 1900275.

28. Bazaz, S.R., Kashaninejad, N., Azadi, S., Patel, K., Asadnia, M., Jin, D., and Warkiani, M.E. (2019) Rapid Softlithography Using 3D-Printed Molds. Adv. Mater. Technol, 4 (10), 1900425.

29. Hiltunen, J., Liedert, C., Hiltunen, M., Huttunen, O.-H., Hiitola-Keinänen, J., Aikio, S., Harjanne, M., Kurkinen, M., Hakalahti, L., and Lee, L.P. (2018) Roll-to-roll fabrication of integrated PDMS-paper microfluidics for nucleic acid amplification. Lab Chip, 18 (11), 15521559.

30. Senkbeil, S., Aho, J., Yde, L., Lindvold, L.R., Stensborg, J.F., Rantanen, J., Lafleur, J.P., and Kutter, J.P. (2016) Roll-to-plate fabrication of microfluidic devices with rheology-modified thiol-ene resins. J. Micromech. Microeng., 26 (7), 075014.

31. Zhu, D., Long, Q., Xu, Y., and Xing, J. (2019) Evaluating Nanoparticles in Preclinical Research Using Microfluidic Systems. Micromachines (Basel), 10 (6).

32. Paguirigan, A.L., and Beebe, D.J. (2009) From the cellular perspective: exploring differences in the cellular baseline in macroscale and microfluidic cultures. Int Bio (Cam), 1 (2), 182-195.

33. Halldorsson, S., Lucumi, E., Gómez-Sjöberg, R., and Fleming, R.M.T. (2015) Advantages and challenges of microfluidic cell culture in polydimethylsiloxane devices. Biosens. Bioelectron., 63, 218-231.

34. Firpo, G., Angeli, E., Repetto, L., and Valbusa, U. (2015) Permeability thickness dependence of polydimethylsiloxane (PDMS) membranes. J. Membrane Sci, 481, 1-8.

35. Käpylä, E., Sorkio, A., Teymouri, S., Lahtonen, K., Vuori, L., Valden, M., Skottman, H., Kellomäki, M., and Juuti-Uusitalo, K. (2014) Ormocomp-Modified Glass Increases Collagen Binding and Promotes the Adherence and Maturation of Human Embryonic Stem CellDerived Retinal Pigment Epithelial Cells. Langmuir, 30 (48), 14555-14565.

36. Klein, F., Richter, B., Striebel, T., Franz, C.M., Freymann, G. von, Wegener, M., and Bastmeyer, M. (2011) Two-Component Polymer Scaffolds for Controlled Three-Dimensional Cell Culture. Adv. Mater., 23 (11), 1341-1345.

37. Schlie, S., Ngezahayo, A., Ovsianikov, A., Fabian, T., Kolb, H.-A., Haferkamp, H., and Chichkov, B.N. (2007) Three-Dimensional Cell Growth on Structures Fabricated from ORMOCER $®$ by Two-Photon Polymerization Technique. J Biomater Appl, 22 (3), 275-287.

38. Lu, H., Koo, L.Y., Wang, W.M., Lauffenburger, D.A., Griffith, L.G., and Jensen, K.F. (2004) Microfluidic Shear Devices for Quantitative Analysis of Cell Adhesion. Anal. Chem., 76 (18), 5257-5264. 
39. van der Meer, A.D., Poot, A.A., Duits, M.H.G., Feijen, J., and Vermes, I. (2009) Microfluidic Technology in Vascular Research. J. Biomed. Biotechnol. 823148.

40. Gough, J.E., and Downes, S. (2001) Osteoblast cell death on methacrylate polymers involves apoptosis. J. Biomed. Mater. Res., 57 (4), 497-505.

41. Piironen, K., Haapala, M., Järvinen, P., and Sikanen, T. (2018) Cell Proliferation on Common 3D Printing Materials Used in Stereolithographic Patterning of Microfluidic Devices.

Proceedings of the 22nd International Conference on Miniaturized Systems for Chemistry and Life Sciences (MicroTAS 2018), 1469-1472.

42. Piironen, K., Järvinen, P., Kiiski, I., and Sikanen, T. (2019) Understanding Cell Proliferation and Material-Induced Cell Death on Microfluidic Devices Made of Off-Stoichiometric ThiolEnes. Proceedings of the 23rd International Conference on Miniaturized Systems for Chemistry and Life Sciences (MicroTAS 2019), 316-317.

43. Sticker, D., Rothbauer, M., Ehgartner, J., Steininger, C., Liske, O., Liska, R., Neuhaus, W., Mayr, T., Haraldsson, T., Kutter, J.P., and Ertl, P. (2019) Oxygen Management at the Microscale: A Functional Biochip Material with Long-Lasting and Tunable Oxygen Scavenging Properties for Cell Culture Applications. ACS Appl. Mater. Interfaces, 11 (10), 9730-9739.

44. Haque, A., Gheibi, P., Gao, Y., Foster, E., Son, K.J., You, J., Stybayeva, G., Patel, D., and Revzin, A. (2016) Cell biology is different in small volumes: endogenous signals shape phenotype of primary hepatocytes cultured in microfluidic channels. Sci Rep. 6, 33980.

45. Piruska, A., Nikcevic, I., Lee, S.H., Ahn, C., Heineman, W.R., Limbach, P.A., and Seliskar, C.J. (2005) The autofluorescence of plastic materials and chips measured under laser irradiation. Lab Chip, 5 (12), 1348-1354.

46. Aura, S., Sikanen, T., Kotiaho, T., and Franssila, S. (2008) Novel hybrid material for microfluidic devices. Sensors Act. B, 132 (2), 397-403.

47. Feidenhans'1, N.A., Lafleur, J.P., Jensen, T.G., and Kutter, J.P. (2014) Surface functionalized thiol-ene waveguides for fluorescence biosensing in microfluidic devices. Electrophoresis, $\mathbf{3 5}$ (2-3), 282-288.

48. Hartcher-O'Brien, J., Evers, J., and Tempelman, E. (2019) Surface roughness of 3D printed materials: Comparing physical measurements and human perception. Mater. Today Commun., 19, 300-305.

49. Chawla, K., Bürgel, S.C., Schmidt, G.W., Kaltenbach, H.-M., Rudolf, F., Frey, O., and Hierlemann, A. (2018) Integrating impedance-based growth-rate monitoring into a microfluidic cell culture platform for live-cell microscopy. Microsyst. Nanoeng., 4 (1), 1-12.

50. Reiss, B., and Wegener, J. (2015) Impedance analysis of different cell monolayers grown on gold-film electrodes. 2015 37th Annual International Conference of the IEEE Engineering in Medicine and Biology Society (EMBC), 7079-7082.

51. Choi, Y.H., Min, J., and Cho, S. (2015) Indium tin oxide based chip for optical and electrochemical characterization of protein-cell interaction. Jpn. J. Appl. Phys., 54 (6S1), 06FN03.

52. Ryspayeva, A., Jones, T.D.A., Esfahani, M.N., Shuttleworth, M.P., Harris, R.A., Kay, R.W., Desmulliez, M.P.Y., and Marques-Hueso, J. (2019) A rapid technique for the direct metallization of PDMS substrates for flexible and stretchable electronics applications. Microelectron. Eng., 209, 35-40.

53. Bonabi, A., Tähkä, S., Ollikainen, E., Jokinen, V., and Sikanen, T. (2019) Metallization of Organically Modified Ceramics for Microfluidic Electrochemical Assays. Micromachines, 10 (9).

54. Wenger, R.H., Kurtcuoglu, V. Scholz, C.C., Marti, H.H., Hoogewiijs, D. (2015).Frequently asked questions in hypoxia research. Hypoxia (Auckl). 3, 35-43.

55. Barmaki, S., Jokinen, V., Obermaier, D., Blokhina, D., Korhonen, M., Ras, R.H.A., Vuola, J., Franssila, S., and Kankuri, E. (2018) A microfluidic oxygen sink to create a targeted cellular 
hypoxic microenvironment under ambient atmospheric conditions. Acta Biomater., 73, 167179.

56. Brennan, M.D., Rexius-Hall, M.L., Elgass, L.J., and Eddington, D.T. (2014) Oxygen control with microfluidics. Lab Chip, 14 (22), 4305-4318.

57. Kim, D.-H., Lipke, E.A., Kim, P., Cheong, R., Thompson, S., Delannoy, M., Suh, K.-Y., Tung, L., and Levchenko, A. (2010) Nanoscale cues regulate the structure and function of macroscopic cardiac tissue constructs. PNAS, 107 (2), 565-570.

58. Rao, C., Prodromakis, T., Kolker, L., Chaudhry, U.A.R., Trantidou, T., Sridhar, A., Weekes, C., Camelliti, P., Harding, S.E., Darzi, A., Yacoub, M.H., Athanasiou, T., and Terracciano, C.M. (2013) The effect of microgrooved culture substrates on calcium cycling of cardiac myocytes derived from human induced pluripotent stem cells. Biomaterials, 34 (10), 2399_ 2411.

59. Kim, J.Y., Choi, Y.-S., Lee, B.-K., and Lee, D.-W. (2016) Surface-patterned SU-8 cantilever arrays for preliminary screening of cardiac toxicity. Biosens. Bioelectron., 80, 456-462.

60. Anene-Nzelu, C.G., Peh, K.Y., Fraiszudeen, A., Kuan, Y.H., Ng, S.H., Toh, Y.C., Leo, H.L., and $\mathrm{Yu}, \mathrm{H}$. (2013) Scalable alignment of three-dimensional cellular constructs in a microfluidic chip. Lab Chip, 13 (20), 4124-4133.

61. Boroujeni, S.M., Mashayekhan, S., Vakilian, S., Ardeshirylajimi, A., and Soleimani, M. (2016) The synergistic effect of surface topography and sustained release of TGF- $\beta 1$ on myogenic differentiation of human mesenchymal stem cells. J. Biomed. Mater Res. Part A, 104 (7), 1610-1621.

62. Castiaux, A.D., Spence, D.M., and Martin, R.S. (2019) Review of 3D cell culture with analysis in microfluidic systems. Anal. Methods, 11 (33), 4220-4232.

63. Duval, K., Grover, H., Han, L.-H., Mou, Y., Pegoraro, A.F., Fredberg, J., and Chen, Z. (2017) Modeling Physiological Events in 2D vs. 3D Cell Culture. Physiology, 32 (4), 266-277.

64. Pampaloni, F., Reynaud, E.G., and Stelzer, E.H.K. (2007) The third dimension bridges the gap between cell culture and live tissue. Nature Rev. Mol. Cell Biol., 8 (10), 839-845.

65. Cukierman, E., Pankov, R., Stevens, D.R., and Yamada, K.M. (2001) Taking Cell-Matrix Adhesions to the Third Dimension. Science, 294 (5547), 1708-1712.

66. Nath, S., and Devi, G.R. (2016) Three-dimensional culture systems in cancer research: Focus on tumor spheroid model. Pharmacol.Ther., 163, 94-108.

67. Godoy, P., Hewitt, N.J., Albrecht, U., Andersen, M.E., Ansari, N., Bhattacharya, S., Bode, J.G., Bolleyn, J., Borner, C., Böttger, J., Braeuning, A., Budinsky, R.A., Burkhardt, B., Cameron, N.R., Camussi, G., Cho, C.-S., Choi, Y.-J., Craig Rowlands, J., Dahmen, U., Damm, G., Dirsch, O., Donato, M.T., Dong, J., Dooley, S., Drasdo, D., Eakins, R., Ferreira, K.S., Fonsato, V., Fraczek, J., Gebhardt, R., Gibson, A., Glanemann, M., Goldring, C.E.P., GómezLechón, M.J., Groothuis, G.M.M., Gustavsson, L., Guyot, C., Hallifax, D., Hammad, S., Hayward, A., Häussinger, D., Hellerbrand, C., Hewitt, P., Hoehme, S., Holzhütter, H.-G., Houston, J.B., Hrach, J., Ito, K., Jaeschke, H., Keitel, V., Kelm, J.M., Kevin Park, B., Kordes, C., Kullak-Ublick, G.A., LeCluyse, E.L., Lu, P., Luebke-Wheeler, J., Lutz, A., Maltman, D.J., Matz-Soja, M., McMullen, P., Merfort, I., Messner, S., Meyer, C., Mwinyi, J., Naisbitt, D.J., Nussler, A.K., Olinga, P., Pampaloni, F., Pi, J., Pluta, L., Przyborski, S.A., Ramachandran, A., Rogiers, V., Rowe, C., Schelcher, C., Schmich, K., Schwarz, M., Singh, B., Stelzer, E.H.K., Stieger, B., Stöber, R., Sugiyama, Y., Tetta, C., Thasler, W.E., Vanhaecke, T., Vinken, M., Weiss, T.S., Widera, A., Woods, C.G., Xu, J.J., Yarborough, K.M., and Hengstler, J.G. (2013) Recent advances in 2D and 3D in vitro systems using primary hepatocytes, alternative hepatocyte sources and non-parenchymal liver cells and their use in investigating mechanisms of hepatotoxicity, cell signaling and ADME. Arch Toxicol, 87 (8), 1315-1530.

68. Verjans, E.-T., Doijen, J., Luyten, W., Landuyt, B., and Schoofs, L. (2018) Three-dimensional cell culture models for anticancer drug screening: Worth the effort? J. Cellular Physiol., 233 (4), 2993-3003. 
69. Vadivelu, R.K., Kamble, H., Shiddiky, M.J.A., and Nguyen, N.-T. (2017) Microfluidic Technology for the Generation of Cell Spheroids and Their Applications. Micromachines, 8 (4).

70. Liao, J., Guo, X., Grande-Allen, K.J., Kasper, F.K., and Mikos, A.G. (2010) Bioactive polymer/extracellular matrix scaffolds fabricated with a flow perfusion bioreactor for cartilage tissue engineering. Biomaterials, 31 (34), 8911-8920.

71. Otsuka, H., Nagamura, M., Kaneko, A., Kutsuzawa, K., Sakata, T., and Miyahara, Y. (2012) Chondrocyte spheroids on microfabricated PEG hydrogel surface and their noninvasive functional monitoring. Sci Technol Adv Mater, 13 (6).

72. Jokinen, V., Kankuri, E., Hoshian, S., Franssila, S., and Ras, R.H.A. (2018) Superhydrophobic Blood-Repellent Surfaces. Adv. Mater., 30 (24), 1705104.

73. Oliveira, S.M., Song, W., Alves, N.M., and Mano, J.F. (2011) Chemical modification of bioinspired superhydrophobic polystyrene surfaces to control cell attachment/proliferation. Soft Matter, 7 (19), 8932-8941.

74. Wang, G.-J., Ho, K.-H., Hsu, S., and Wang, K.-P. (2007) Microvessel scaffold with circular microchannels by photoresist melting. Biomed Microdevices, 9 (5), 657-663.

75. Camp, J.P., Stokol, T., and Shuler, M.L. (2008) Fabrication of a multiple-diameter branched network of microvascular channels with semi-circular cross-sections using xenon difluoride etching. Biomed Microdevices, 10 (2), 179-186.

76. Tu, T.-Y., Wang, Z., Bai, J., Sun, W., Peng, W.K., Huang, R.Y.-J., Thiery, J.-P., and Kamm, R.D. (2014) Rapid prototyping of concave microwells for the formation of 3D multicellular cancer aggregates for drug screening. Adv Healthc Mater, 3 (4), 609-616.

77. Ma, L.-D., Wang, Y.-T., Wang, J.-R., Wu, J.-L., Meng, X.-S., Hu, P., Mu, X., Liang, Q.-L., and Luo, G.-A. (2018) Design and fabrication of a liver-on-a-chip platform for convenient, highly efficient, and safe in situ perfusion culture of 3D hepatic spheroids. Lab Chip, 18 (17), 2547-2562.

78. Moshksayan, K., Kashaninejad, N., Warkiani, M.E., Lock, J.G., Moghadas, H., Firoozabadi, B., Saidi, M.S., and Nguyen, N.-T. (2018) Spheroids-on-a-chip: Recent advances and design considerations in microfluidic platforms for spheroid formation and culture. Sensors Act. B, 263, 151-176.

79. Rodrigues, R.O., Bañobre-López, M., Gallo, J., Tavares, P.B., Silva, A.M.T., Lima, R., and Gomes, H.T. (2016) Haemocompatibility of iron oxide nanoparticles synthesized for theranostic applications: a high-sensitivity microfluidic tool. J Nanopart Res, 18 (7), 194.

80. Falanga, A.P., Pitingolo, G., Celentano, M., Cosentino, A., Melone, P., Vecchione, R., Guarnieri, D., and Netti, P.A. (2017) Shuttle-mediated nanoparticle transport across an in vitro brain endothelium under flow conditions. Biotechnol. Bioeng., 114 (5), 1087-1095.

81. Huh, D., Matthews, B.D., Mammoto, A., Montoya-Zavala, M., Hsin, H.Y., and Ingber, D.E. (2010) Reconstituting Organ-Level Lung Functions on a Chip. Science, 328 (5986), 16621668.

82. Stylianopoulos, T., and Jain, R.K. (2015) Design considerations for nanotherapeutics in oncology. Nanomed.: Nanotech. Biol.Med., 11 (8), 1893-1907.

83. Zhang, Y.-N., Poon, W., Tavares, A.J., McGilvray, I.D., and Chan, W.C.W. (2016) Nanoparticle-liver interactions: Cellular uptake and hepatobiliary elimination. Journal of Controlled Rel., 240, 332-348.

84. Ragelle, H., Danhier, F., Préat, V., Langer, R., and Anderson, D.G. (2017) Nanoparticle-based drug delivery systems: a commercial and regulatory outlook as the field matures. Expert Opin. Drug Deliv., 14 (7), 851-864.

85. Yu, M., and Zheng, J. (2015) Clearance Pathways and Tumor Targeting of Imaging Nanoparticles. ACS Nano, 9 (7), 6655-6674.

86. Maeda, H. (2012) Macromolecular therapeutics in cancer treatment: The EPR effect and beyond. J. Controlled Rel., 164 (2), 138-144. 
87. Matsumura, Y., and Maeda, H. (1986) A New Concept for Macromolecular Therapeutics in Cancer Chemotherapy: Mechanism of Tumoritropic Accumulation of Proteins and the Antitumor Agent Smancs. Cancer Res, 46 (12 Part 1), 6387-6392.

88. Haute, D.V., and Berlin, J.M. (2017) Challenges in realizing selectivity for nanoparticle biodistribution and clearance: lessons from gold nanoparticles. Ther. Deliv., 8 (9), 763-774.

89. Tsoi, K.M., MacParland, S.A., Ma, X.-Z., Spetzler, V.N., Echeverri, J., Ouyang, B., Fadel, S.M., Sykes, E.A., Goldaracena, N., Kaths, J.M., Conneely, J.B., Alman, B.A., Selzner, M., Ostrowski, M.A., Adeyi, O.A., Zilman, A., McGilvray, I.D., and Chan, W.C.W. (2016) Mechanism of hard-nanomaterial clearance by the liver. Nature Mater., 15 (11), 1212-1221.

90. Cormode, D.P., Skajaa, G.O., Delshad, A., Parker, N., Jarzyna, P.A., Calcagno, C., Galper, M.W., Skajaa, T., Briley-Saebo, K.C., Bell, H.M., Gordon, R.E., Fayad, Z.A., Woo, S.L.C., and Mulder, W.J.M. (2011) A Versatile and Tunable Coating Strategy Allows Control of Nanocrystal Delivery to Cell Types in the Liver. Bioconjugate Chem., 22 (3), 353-361.

91. Cheng, S.-H., Li, F.-C., Souris, J.S., Yang, C.-S., Tseng, F.-G., Lee, H.-S., Chen, C.-T., Dong, C.-Y., and Lo, L.-W. (2012) Visualizing Dynamics of Sub-Hepatic Distribution of Nanoparticles Using Intravital Multiphoton Fluorescence Microscopy. ACS Nano, 6 (5), 4122 4131.

92. Zanger, U.M., and Schwab, M. (2013) Cytochrome P450 enzymes in drug metabolism: Regulation of gene expression, enzyme activities, and impact of genetic variation. Pharmacol. Ther., 138 (1), 103-141.

93. Zhou, S.F., Liu, J.P., Lai, X.S. (2009) Substrate specificity, inhibitors and regulation of human cytochrome P450 2D6 and implications in drug development. Curr. Med. Chem. 16 (21), 2661-805.

94. Brandon, E.F.A., Raap, C.D., Meijerman, I., Beijnen, J.H., and Schellens, J.H.M. (2003) An update on in vitro test methods in human hepatic drug biotransformation research: pros and cons. Toxicol. Appl. Pharmacol., 189 (3), 233-246.

95. Fasinu, P., Bouic, P.J., and Rosenkranz, B. (2012) Liver-Based In Vitro Technologies for Drug Biotransformation Studies - A Review. Current Drug Metab., 13 (2), 215-224.

96. Fowler, S., and Zhang, H. (2008) In Vitro Evaluation of Reversible and Irreversible Cytochrome P450 Inhibition: Current Status on Methodologies and their Utility for Predicting Drug-Drug Interactions. AAPS J, 10 (2), 410-424.

97. Kumar, S. (2010) Engineering cytochrome P450 biocatalysts for biotechnology, medicine and bioremediation. Expert Opin. Drug Metab. Toxicol., 6 (2), 115-131.

98. Midde, N.M., and Kumar, S. (2015) Development of NanoART for HIV treatment: minding the cytochrome P450 (CYP) enzymes. J Pers Nanomed, 1, 24-32.

99. Lamb, J.G., Hathaway, L.B., Munger, M.A., Raucy, J.L., and Franklin, M.R. (2010) Nanosilver Particle Effects on Drug Metabolism in Vitro. Drug Metab Dispos, 8 (12), 2246-2251.

100. Warisnoicharoen, W., Hongpiticharoen, P., and Lawanprasert, S. (2011) Alteration in Enzymatic Function of Human Cytochrome P450 by Silver Nanoparticles. Res. J. Environ. Toxicol., 5 (1), 58-64.

101. Kulthong, K., Maniratanachote, R., Kobayashi, Y., Fukami, T., and Yokoi, T. (2012) Effects of silver nanoparticles on rat hepatic cytochrome P450 enzyme activity. Xenobiotica, 42 (9), 854-862.

102. Balasubramanian, S.K., Jittiwat, J., Manikandan, J., Ong, C.-N., Yu, L.E., and Ong, W.-Y. (2010) Biodistribution of gold nanoparticles and gene expression changes in the liver and spleen after intravenous administration in rats. Biomaterials, 31 (8), 2034-2042.

103. Ye, M., Tang, L., Luo, M., Zhou, J., Guo, B., Liu, Y., and Chen, B. (2014) Size- and timedependent alteration in metabolic activities of human hepatic cytochrome P450 isozymes by gold nanoparticles via microsomal coincubations. Nanoscale Res. Lett., 9 (1), 642.

104. Sereemaspun, A., Hongpiticharoen, P., Rojanathanes, R., Maneewattanapinyo, P., Ekgasit, S., and Warisnoicharoen, W. (2008) Inhibition of Human Cytochrome P450 Enzymes by Metallic Nanoparticles: A Preliminary to Nanogenomics. Int. J. Pharmacol., 4 (6), 492-495. 
105. Fröhlich, E., Kueznik, T., Samberger, C., Roblegg, E., Wrighton, C., and Pieber, T.R. (2010) Size-dependent effects of nanoparticles on the activity of cytochrome P450 isoenzymes. Toxicol. Applied Pharmacol., 242 (3), 326-332.

106. Lee, M.-Y., Yang, J.-A., Jung, H.S., Beack, S., Choi, J.E., Hur, W., Koo, H., Kim, K., Yoon, S.K., and Hahn, S.K. (2012) Hyaluronic Acid-Gold Nanoparticle/Interferon $\alpha$ Complex for Targeted Treatment of Hepatitis C Virus Infection. ACS Nano, 6 (11), 9522-9531.

107. Yang, Y., Yuan, S.-X., Zhao, L.-H., Wang, C., Ni, J.-S., Wang, Z.-G., Lin, C., Wu, M.-C., and Zhou, W.-P. (2015) Ligand-Directed Stearic Acid Grafted Chitosan Micelles to Increase Therapeutic Efficacy in Hepatic Cancer. Mol. Pharmaceutics, 12 (2), 644-652.

108. Ollikainen, E., Liu, D., Kallio, A., Mäkilä, E., Zhang, H., Salonen, J., Santos, H.A., and Sikanen, T.M. (2017) The impact of porous silicon nanoparticles on human cytochrome P450 metabolism in human liver microsomes in vitro. Eur. J. Pharm. Sci, 104, 124-132.

109. Gay, S.C., Roberts, A.G., and Halpert, J.R. (2010) Structural Features of Cytochromes P450 and Ligands that Affect Drug Metabolism as Revealed by X-ray Crystallography and NMR. Future Med Chem, 2 (9), 1451-1468.

110. EUNCL | Nanomedicine Characterisation Laboratory.

111. Hadd, A.G., Raymond, D.E., Halliwell, J.W., Jacobson, S.C., and Ramsey, J.M. (1997) Microchip Device for Performing Enzyme Assays. Anal. Chem., 69 (17), 3407-3412.

112. Cohen, C.B., Chin-Dixon, E., Jeong, S., and Nikiforov, T.T. (1999) A Microchip-Based Enzyme Assay for Protein Kinase A. Anal. Biochem., 273 (1), 89-97.

113. Mao, H., Yang, T., and Cremer, P.S. (2002) Design and Characterization of Immobilized Enzymes in Microfluidic Systems. Anal. Chem., 74 (2), 379-385.

114. Křenková, J., and Foret, F. (2004) Immobilized microfluidic enzymatic reactors. Electrophoresis, 25 (21-22), 3550-3563.

115. Munro, A.W., Girvan, H.M., and McLean, K.J. (2007) Variations on a (t)heme-novel mechanisms, redox partners and catalytic functions in the cytochrome P450 superfamily. Nat. Prod. Rep., 24 (3), 585-609.

116. Munro, A.W., Girvan, H.M., Mason, A.E., Dunford, A.J., and McLean, K.J. (2013) What makes a P450 tick? Trends Biochem. Sci, 38 (3), 140-150.

117. Imaoka, S., Imai, Y., Shimada, T., and Funae, Y. (1992) Role of phospholipids in reconstituted cytochrome $\mathrm{P} 4503 \mathrm{~A}$ form and mechanism of their activation of catalytic activity. Biochemistry, 31 (26), 6063-6069.

118. Pearce, R.E., McIntyre, C.J., Madan, A., Sanzgiri, U., Draper, A.J., Bullock, P.L., Cook, D.C., Burton, L.A., Latham, J., Nevins, C., and Parkinson, A. (1996) Effects of Freezing, Thawing, and Storing Human Liver Microsomes on Cytochrome P450 Activity. Arch. Biochem. Biophys., 331 (2), 145-169.

119. Busby, W.F., Ackermann, J.M., and Crespi, C.L. (1999) Effect of methanol, ethanol, dimethyl sulfoxide, and acetonitrile on in vitro activities of cDNA-expressed human cytochromes P450. Drug Metab. Dispos., 27 (2), 246-249.

120. Foti, R.S., and Fisher, M.B. (2004) Impact of Incubation Conditions on Bufuralol Human Clearance Predictions: Enzyme Lability and Nonspecific Binding. Drug Metab Dispos, 32 (3), 295-304.

121. Karuzina, I.I., and Archakov, A.I. (1994) Hydrogen peroxide-mediated inactivation of microsomal cytochrome P450 during monooxygenase reactions. Free Radical Biol. Med., 17 (6), 557-567.

122. Sassolas, A., Blum, L.J., and Leca-Bouvier, B.D. (2012) Immobilization strategies to develop enzymatic biosensors. Biotechnol. Adv., 30 (3), 489-511.

123. Kim, D., and Herr, A.E. (2013) Protein immobilization techniques for microfluidic assays. Biomicrofluidics, 7 (4), 041501.

124. Datta, S., Christena, L.R., and Rajaram, Y.R.S. (2013) Enzyme immobilization: an overview on techniques and support materials. 3 Biotech, 3 (1), 1-9. 
125. Sheldon, R.A. (2007) Enzyme Immobilization: The Quest for Optimum Performance. Adv. Synthesis Cat., 349 (8-9), 1289-1307.

126. Sakai-Kato, K., Kato, M., Homma, H., Toyo'oka, T., and Utsunomiya-Tate, N. (2005) Creation of a P450 Array toward High-throughput Analysis. Anal. Chem., 77 (21), 7080-7083.

127. Zguris, J.C., Itle, L.J., Hayes, D., and Pishko, M.V. (2005) Microreactor Microfluidic Systems with Human Microsomes and Hepatocytes for use in Metabolite Studies. Biomed Microdevices, 7 (2), 117-125.

128. A. Sheldon, R., and Pelt, S. van (2013) Enzyme immobilisation in biocatalysis: why, what and how. Chem. Soc. Rev., 42 (15), 6223-6235.

129. Honiger, J., Balladur, P., Mariani, P., Calmus, Y., Vaubourdolle, M., Delelo, R., Capeau, J., and Nordlinger, B. (1995) Permeability and biocompatibility of a new hydrogel used for encapsulation of hepatocytes. Biomaterials, 16 (10), 753-759.

130. Wu, Q., Gao, D., Wei, J., Jin, F., Xie, W., Jiang, Y., and Liu, H. (2014) Development of a novel multi-layer microfluidic device towards characterization of drug metabolism and cytotoxicity for drug screening. Chem. Commun., 50 (21), 2762-2764.

131. Tan, C.Y., Hirakawa, H., and Nagamune, T. (2015) Supramolecular protein assembly supports immobilization of a cytochrome P450 monooxygenase system as water-insoluble gel. Sci Rep., $5(1), 1-8$.

132. Do, M.Q., Henry, E., Kato, M., and Cheruzel, L. (2018) Cross-linked cytochrome P450 BM3 aggregates promoted by $\mathrm{Ru}(\mathrm{II})$-diimine complexes bearing aldehyde groups. J. Inorg. Biochem., 186, 130-134.

133. Luo, Q., Mao, X., Kong, L., Huang, X., and Zou, H. (2002) High-performance affinity chromatography for characterization of human immunoglobulin $\mathrm{G}$ digestion with papain. $J$. Chromatogr. B, 776 (2), 139-147.

134. Wong, L.S., Khan, F., and Micklefield, J. (2009) Selective Covalent Protein Immobilization: Strategies and Applications. Chem. Rev., 109 (9), 4025-4053.

135. Tudorache, M., Mahalu, D., Teodorescu, C., Stan, R., Bala, C., and Parvulescu, V.I. (2011) Biocatalytic microreactor incorporating HRP anchored on micro-/nano-lithographic patterns for flow oxidation of phenols. J. Mol. Cat. B, 69 (3), 133-139.

136. Schejbal, J., Řemínek, R., Zeman, L., Mádr, A., and Glatz, Z. (2016) On-line coupling of immobilized cytochrome P450 microreactor and capillary electrophoresis: A promising tool for drug development. J. Chromatogr. A, 1437, 234-240.

137. Wollenberg, L.A., Kabulski, J.L., Powell, M.J., Chen, J., Flora, D.R., Tracy, T.S., and Gannett, P.M. (2014) The Use of Immobilized Cytochrome P4502C9 in PMMA-Based Plug Flow Bioreactors for the Production of Drug Metabolites. Appl Biochem Biotechnol, 172 (3), 1293-1306.

138. Ménard, A., Huang, Y., Karam, P., Cosa, G., and Auclair, K. (2012) Site-Specific Fluorescent Labeling and Oriented Immobilization of a Triple Mutant of CYP3A4 via C64. Bioconjugate Chem., 23 (4), 826-836.

139. Gannett, P.M., Kabulski, J., Perez, F.A., Liu, Z., Lederman, D., Locuson, C.W., Ayscue, R.R., Thomsen, N.M., and Tracy, T.S. (2006) Preparation, Characterization, and Substrate Metabolism of Gold-Immobilized Cytochrome P450 2C9. J. Am. Chem. Soc., 128 (26), 83748375.

140. Jesionowski, T., Zdarta, J., and Krajewska, B. (2014) Enzyme immobilization by adsorption: a review. Adsorption, 20 (5), 801-821.

141. Nicoli, R., Bartolini, M., Rudaz, S., Andrisano, V., and Veuthey, J.-L. (2008) Development of immobilized enzyme reactors based on human recombinant cytochrome P450 enzymes for phase I drug metabolism studies. J. Chromatogr. A, 1206 (1), 2-10.

142. Kiiski, I.M.A., Pihlaja, T., Urvas, L., Witos, J., Wiedmer, S.K., Jokinen, V.P., and Sikanen, T.M. (2019) Overcoming the Pitfalls of Cytochrome P450 Immobilization through the Use of Fusogenic Liposomes. Adv. Biosyst., 3 (1), 1800245. 
143. Ueda, Y., Morigaki, K., Tatsu, Y., Yumoto, N., and Imaishi, H. (2007) Immobilization and activity assay of cytochrome P450 on patterned lipid membranes. Biochem. Biophys. Res. Commun., 355 (4), 926-931.

144. Jönsson, A., Svejdal, R.R., Bøgelund, N., Nguyen, T.T.T.N., Flindt, H., Kutter, J.P., Rand, K.D., and Lafleur, J.P. (2017) Thiol-ene Monolithic Pepsin Microreactor with a 3D-Printed Interface for Efficient UPLC-MS Peptide Mapping Analyses. Anal. Chem., 89 (8), 4573-4580.

145. Peterson, D.S., Rohr, T., Svec, F., and Fréchet, J.M.J. (2002) Enzymatic Microreactor-on-aChip: Protein Mapping Using Trypsin Immobilized on Porous Polymer Monoliths Molded in Channels of Microfluidic Devices. Anal. Chem., 74 (16), 4081-4088.

146. Oliver-Calixte, N.J., Uba, F.I., Battle, K.N., Weerakoon-Ratnayake, K.M., and Soper, S.A. (2014) Immobilization of Lambda Exonuclease onto Polymer Micropillar Arrays for the SolidPhase Digestion of dsDNAs. Anal. Chem., 86 (9), 4447-4454.

147. Losey, M.W., Jackman, R.J., Firebaugh, S.L., Schmidt, M.A., and Jensen, K.F. (2002) Design and fabrication of microfluidic devices for multiphase mixing and reaction. $J$.

Microelectromech. Syst., 11 (6), 709-717.

148. Zhu, Y., Chen, Q., Shao, L., Jia, Y., and Zhang, X. (2020) Microfluidic immobilized enzyme reactors for continuous biocatalysis. Reaction Chem. Eng., 5, 9-32.

149. Slovakova, M., Minc, N., Bilkova, Z., Smadja, C., Faigle, W., Fütterer, C., Taverna, M., and Viovy, J.-L. (2005) Use of self assembled magnetic beads for on-chip protein digestion. Lab Chip, 5 (9), 935-942.

150. Vlakh, E.G., and Tennikova, T.B. (2013) Flow-through immobilized enzyme reactors based on monoliths: II. Kinetics study and application. J. Sep. Sci, 36 (6), 1149-1167.

151. Munirathinam, R., Huskens, J., and Verboom, W. (2015) Supported Catalysis in ContinuousFlow Microreactors. Adv. Synthesis Cat., 357 (6), 1093-1123.

152. Burke, J.M., and Smela, E. (2012) A novel surface modification technique for forming porous polymer monoliths in poly(dimethylsiloxane). Biomicrofluidics, 6 (1), 016506.

153. Haapala, M., Saarela, V., Pól, J., Kolari, K., Kotiaho, T., Franssila, S., and Kostiainen, R. (2010) Integrated liquid chromatography-heated nebulizer microchip for mass spectrometry. Anal. Chim. Acta, 662 (2), 163-169.

154. Sainiemi, L., Nissilä, T., Jokinen, V., Sikanen, T., Kotiaho, T., Kostiainen, R., Ketola, R.A., and Franssila, S. (2008) Fabrication and fluidic characterization of silicon micropillar array electrospray ionization chip. Sensors Act. B, 132 (2), 380-387.

155. Amato, L., Keller, S.S., Heiskanen, A., Dimaki, M., Emnéus, J., Boisen, A., and Tenje, M. (2012) Fabrication of high-aspect ratio SU-8 micropillar arrays. Microelectron. Eng., 98, 483487.

156. Hermanson, G. (2013) Bioconjugate Techniques - 3rd Edition, Academic Press, Boston.

157. Lee, J.N., Park, C., and Whitesides, G.M. (2003) Solvent Compatibility of Poly(dimethylsiloxane)-Based Microfluidic Devices. Anal. Chem., 75 (23), 6544-6554.

158. Makamba, H., Kim, J.H., Lim, K., Park, N., and Hahn, J.H. (2003) Surface modification of poly(dimethylsiloxane) microchannels. Electrophoresis, 24 (21), 3607-3619.

159. van Midwoud, P.M., Janse, A., Merema, M.T., Groothuis, G.M.M., and Verpoorte, E. (2012) Comparison of Biocompatibility and Adsorption Properties of Different Plastics for Advanced Microfluidic Cell and Tissue Culture Models. Anal. Chem., 84 (9), 3938-3944.

160. Lafleur, J.P., Kwapiszewski, R., Jensen, T.G., and Kutter, J.P. (2013) Rapid photochemical surface patterning of proteins in thiol-ene based microfluidic devices. Analyst, 138 (3), 845849.

161. Holmberg, K., Tiberg, F., Malmsten, M., and Brink, C. (1997) Grafting with hydrophilic polymer chains to prepare protein-resistant surfaces. Colloids Surf. A, 123-124, 297-306.

162. Moskovitz, Y., and Srebnik, S. (2005) Mean-Field Model of Immobilized Enzymes Embedded in a Grafted Polymer Layer. Biophys J, 89 (1), 22-31. 
163. Tserepi, A., Gogolides, E., Tsougeni, K., Constantoudis, V., and Valamontes, E.S. (2005) Tailoring the surface topography and wetting properties of oxygen-plasma treated polydimethylsiloxane. J. Appl. Phys., 98 (11), 113502.

164. Brown, L., Koerner, T., Hugh Horton, J., and D. Oleschuk, R. (2006) Fabrication and characterization of poly(methylmethacrylate) microfluidic devices bonded using surface modifications and solvents. Lab Chip, 6 (1), 66-73.

165. Goddard, J.M., and Hotchkiss, J.H. (2007) Polymer surface modification for the attachment of bioactive compounds. Progress Polym. Sci, 32 (7), 698-725.

166. Miralles, V., Huerre, A., Malloggi, F., and Jullien, M.-C. (2013) A Review of Heating and Temperature Control in Microfluidic Systems: Techniques and Applications. Diagnostics, 3 (1), 33-67.

167. Lee, C.-Y., Chang, C.-L., Wang, Y.-N., and Fu, L.-M. (2011) Microfluidic Mixing: A Review. Int J Mol Sci, 12 (5), 3263-3287.

168. Sajeesh, P., and Sen, A.K. (2014) Particle separation and sorting in microfluidic devices: a review. Microfluid Nanofluid, 17 (1), 1-52.

169. Iv, C.W.S., Reyes, C.D., and López, G.P. (2015) Microfluidic cell sorting: a review of the advances in the separation of cells from debulking to rare cell isolation. Lab Chip, 15 (5), 1230-1249.

170. Kraly, J.R., Holcomb, R.E., Guan, Q., and Henry, C.S. (2009) Review: Microfluidic Applications in Metabolomics and Metabolic Profiling. Anal Chim Acta, 653 (1), 23-35.

171. Pedde, R.D., Li, H., Borchers, C.H., and Akbari, M. (2017) Microfluidic-Mass Spectrometry Interfaces for Translational Proteomics. Trends Biotechnol., 35 (10), 954-970.

172. Fu, L.-M., Yang, R.-J., Lee, G.-B., and Liu, H.-H. (2002) Electrokinetic Injection Techniques in Microfluidic Chips. Anal. Chem., 74 (19), 5084-5091.

173. Karlinsey, J.M. (2012) Sample introduction techniques for microchip electrophoresis: A review. Anal. Chim. Acta, 725, 1-13.

174. Beattie, J.K. (2006) The intrinsic charge on hydrophobic microfluidic substrates. Lab Chip, 6 (11), 1409-1411.

175. Belder, D., and Ludwig, M. (2003) Surface modification in microchip electrophoresis. Electrophoresis, 24 (21), 3595-3606.

176. Sikanen, T., Aura, S., Franssila, S., Kotiaho, T., and Kostiainen, R. (2012) Microchip capillary electrophoresis-electrospray ionization-mass spectrometry of intact proteins using uncoated Ormocomp microchips. Anal. Chim. Acta, 711, 69-76.

177. Fu, L.M., Tsai, C.H. (2008) Electrokinetic Sample Injection. In: Li, D. (eds) Encyclopedia of Microfluidics and Nanofluidics. Springer, Boston, MA.

178. Kim, M.S., Cho, S.I., Lee, K.N., Kim, Y.K. (2005) Fabrication of microchip electrophoresis devices and effects of channel surface properties on separation efficiency. Sensors Act. B, 107 (2), 818-824.

179. Ollikainen, E., Aitta-aho, T., Koburg, M., Kostiainen, R., and Sikanen, T. (2019) Rapid analysis of intraperitoneally administered morphine in mouse plasma and brain by microchip electrophoresis-electrochemical detection. Sci Rep., 9 (1), 3311.

180. Nordman, N., Sikanen, T., Aura, S., Tuomikoski, S., Vuorensola, K., Kotiaho, T., Franssila, S., Kostiainen, R. (2010) Feasibility of SU-8-based capillary electrophoresis-electrospray ionization mass spectrometry microfluidic chips for the analysis of human cell lysates. Electrophoresis 31 (22), 3745-3753.

181. Vandaveer, W.R., Pasas $\square$ Farmer, S.A., Fischer, D.J., Frankenfeld, C.N., and Lunte, S.M. (2004) Recent developments in electrochemical detection for microchip capillary electrophoresis. Electrophoresis, 25 (21-22), 3528-3549.

182. Sikanen, T., Franssila, S., Kauppila, T.J., Kostiainen, R., Kotiaho, T., and Ketola, R.A. (2010) Microchip technology in mass spectrometry. Mass Spectrom. Rev., 29 (3), 351-391. 
183. Wang, X., Yi, L., Mukhitov, N., Schrell, A.M., Dhumpa, R., and Roper, M.G. (2015) Microfluidics-to-mass spectrometry: A review of coupling methods and applications. $J$. Chromatogr. A, 1382, 98-116.

184. Yuan, X., and Oleschuk, R.D. (2018) Advances in Microchip Liquid Chromatography. Anal. Chem., 90 (1), 283-301.

185. Grinias, J.P., and Kennedy, R.T. (2016) Advances in and prospects of microchip liquid chromatography. TrAC, 81, 110-117.

186. Xie, J., Miao, Y., Shih, J., Tai, Y.-C., and Lee, T.D. (2005) Microfluidic Platform for Liquid Chromatography-Tandem Mass Spectrometry Analyses of Complex Peptide Mixtures. Anal. Chem., 77 (21), 6947-6953.

187. Zhao, C., Ge, Z., and Yang, C. (2017) Microfluidic Techniques for Analytes Concentration. Micromachines, 8 (1), 28.

188. Lichtenberg, J., de Rooij, N.F., and Verpoorte, E. (2002) Sample pretreatment on microfabricated devices. Talanta, 56 (2), 233-266.

189. Mao, S., Gao, D., Liu, W., Wei, H., and Lin, J.-M. (2011) Imitation of drug metabolism in human liver and cytotoxicity assay using a microfluidic device coupled to mass spectrometric detection. Lab Chip, 12 (1), 219-226.

190. Chen, Q., Wu, J., Zhang, Y., and Lin, J.-M. (2012) Qualitative and Quantitative Analysis of Tumor Cell Metabolism via Stable Isotope Labeling Assisted Microfluidic Chip Electrospray Ionization Mass Spectrometry. Anal. Chem., 84 (3), 1695-1701. 